\title{
Soft, Sweet, and Colorful: Stratified Sampling Reveals Sequence of Events at the Onset of Grape Ripening
}

\author{
Esther Hernández-Montes, ${ }^{1,2}$ Yun Zhang, ${ }^{1,3}$ Ben-Min Chang, ${ }^{1}$ \\ Nataliya Shcherbatyuk, ${ }^{1}$ and Markus Keller ${ }^{1 *}$
}

\begin{abstract}
Asynchronous development of grape berries leads to high variation among berry samples collected during veraison. We applied a stratified sampling method that groups berries by firmness to the touch and visible skin color to study the sequence of physical and chemical changes occurring at the onset of and during ripening. Method robustness and reproducibility were tested by measuring berry weight, diameter, deformation, and total soluble solids (TSS) in samples collected from 10 wine, table, and juice grape cultivars varying in skin color. Additionally, Syrah berries sampled by five different individuals were compared in one year, and Syrah and Merlot berry samples and cluster images were evaluated over three years to account for environmental variation. Merlot berries collected in one year were classified into seven developmental stages to measure changes in berry weight, elastic modulus, TSS, titratable acidity (TA), $\mathrm{pH}$, malate, tartrate, and anthocyanins. Stratified sampling reliably differentiated among developmental stages when applied by different individuals and in different cultivars and years. Once the berries softened, they took 11 to 14 days to complete their color change. Softening occurred mostly before sugar accumulation and renewed berry expansion began. Sugar accumulation was concurrent with malate degradation, but its onset preceded anthocyanin accumulation. The increase in TSS was closely associated with decreases in elastic modulus, TA, and malate and increases in berry weight, skin mass per area ratio, and $\mathrm{pH}$. Ripening-related changes in TA and $\mathrm{pH}$ were strongly driven by changes in malate but not tartrate. The stratified sampling method allows novel insights into the timing of physical and chemical changes that occur in grape berries during the period commonly referred to as veraison.
\end{abstract}

Key words: berry development, fruit composition, grape ripening, sampling protocols, veraison, Vitis vinifera

The onset of ripening in grape berries is easily recognized by the change of skin color called "veraison." During this period, the physical and chemical properties of the berry undergo drastic changes in a short period of time, including flesh softening, decrease in cell turgor, resumption of expansive growth, increase in sugar concentration, decrease in

${ }^{1}$ Department of Horticulture, Irrigated Agriculture Research and Extension Center, Washington State University, Prosser, WA; ${ }^{2}$ Plant Biology under Mediterranean Conditions Group, Department of Biology, INAGEA (INIAUIB), University of the Balearic Islands, Palma de Mallorca, Spain; and ${ }^{3}$ Ste. Michelle Wine Estates, Prosser, WA.

*Corresponding author (mkeller@wsu.edu)

Acknowledgments: This work was funded by the Washington State Grape and Wine Research Program, the Chateau Ste. Michelle Distinguished Professorship, the USDA National Institute of Food and Agriculture (Hatch project 1000186), and the Programme for the Training of Researchers of the Spanish Ministry of Economy and Competitiveness (project AGL-2011-30408-C04-01) The authors thank Lynn Mills, Ángela Sánchez, and Alan Kawakami for skilled technical assistance.

Supplemental data is freely available with the online version of this article at www.ajevonline.org.

Manuscript submitted Aug 2020, revised Oct 2020, accepted Nov 2020

This is an open access article distributed under the CC BY license (https:// creativecommons.org/licenses/by/4.0/).

By downloading and/or receiving this article, you agree to the Disclaimer of Warranties and Liability. The full statement of the Disclaimers is available at http://www.ajevonline.org/content/proprietary-rights-notice-ajev-online. If you do not agree to the Disclaimers, do not download and/or accept this article. doi: 10.5344/ajev.2020.20050 acidity, chlorophyll degradation, anthocyanin accumulation in dark-skinned grapes, and other alterations (Keller 2020). These changes occur asynchronously among individual grape berries on the same cluster (Coombe 1992, Lund et al. 2008, Gouthu et al. 2014, Zhang and Keller 2015, 2017). The factors that determine this asynchronous ripening onset remain under study. The correlations that were found between berry size, weight, firmness, color, and global gene transcription profile indicated that individual berries follow distinct developmental timing patterns (Coombe 1992, Lund et al. 2008). These patterns have been linked to the seed content and changes in ripening-related hormones in individual berries (Gouthu and Deluc 2015, Vondras et al. 2016).

In studies on grape ripening, sequential berry samples are commonly classified based either on the calendar (e.g., days after bloom or anthesis) or on phenology (e.g., before, during, and after veraison). With both sampling methods, berries are randomly collected from different parts of a fruit cluster, often at fixed time intervals. Because veraison is usually defined as a certain proportion (e.g., 50\%) of the berries on a cluster or plant or across a vineyard having changed color, random sampling implies collecting berries of varying skin color and firmness at the same time within the same cluster (Figure 1). Because of this inherent berry heterogeneity, these sampling strategies miss both the magnitude of the changes occurring over a short period and their temporal sequence, and thus may mask important changes during the initiation of ripening. In their review of grape ripening, Kuhn et al. (2014) listed the heterogeneity of berry ripening within fruit 
clusters among several obstacles that slow down progress in understanding ripening.

In the model fruit species tomato, by contrast with grapes, it has long been standard practice to group fruit developmental stages by external color, such as immature green, mature green, breaker, turning, pink, light red, and red ripe (e.g., Gillaspy et al. 1993, Saladié et al. 2007). Adopting this approach, our lab began grouping berries visually according to external color (i.e., green, blush, pink, red, purple, blue) to investigate ripening-related changes such as xylem functionality (Keller et al. 2006, 2015) or solute accumulation in the berry vacuoles and apoplast (Keller and Shrestha 2014). Several studies added firmness to the touch (i.e., green hard, green soft) in addition to skin color to investigate berry transpiration (Zhang and Keller 2015), vascular flows (Zhang and Keller 2017), skin rheological properties (Chang et al. 2019), or gene expression (Lund et al. 2008, Gouthu et al. 2014) on phenotypically similar berries. Another approach is sorting berries into density classes by floating them in salt solutions (Bigard et al. 2019). However, recent studies about developmental changes in enzyme activities and gene expression profiles continued using calendar- or phenology-based sampling methods (Famiani et al. 2018, Fasoli et al. 2018, Savoi et al. 2019, Zhu et al. 2020). Therefore, we describe here a reliable method to study the sequence of key changes that occur at the onset of and during grape berry ripening. The main objectives of this work were to i) develop and test a stratified sampling method to quantify physical and chemical attributes during berry ripening with special emphasis on the onset of ripening,

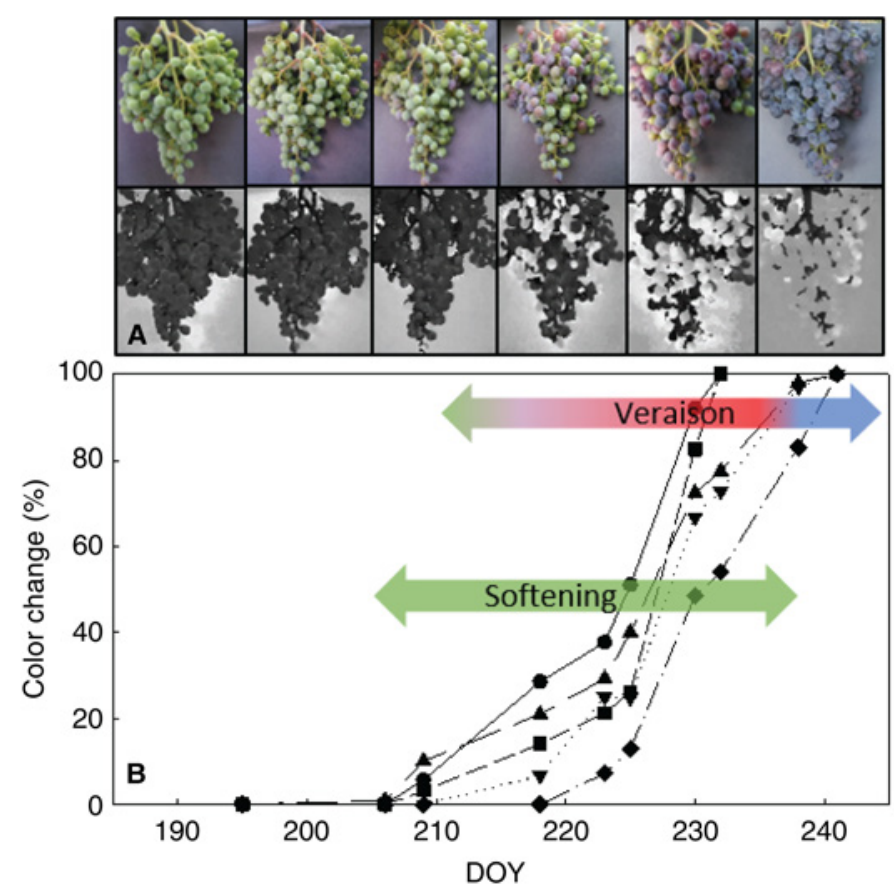

Figure 1 Progression of color change during veraison of Merlot grape clusters in southeastern Washington in 2016. (A) Color images were transformed to gray scale using ImageJ to quantify the rate of color change. (B) Percentage color change over successive days of year (DOY) as estimated from the transformed images. Different symbols and lines represent five individual clusters. and ii) study the relationships between the different attributes during berry ripening. This study provides important insights into the timing and magnitude of changes that occur at the onset of and throughout grape ripening.

\section{Materials and Methods}

Site and plant material. Grape berry samples were collected during 2014, 2015, and 2016 in vineyards located at the Irrigated Agriculture Research and Extension Center in Prosser, Washington ( $46^{\circ} 3^{\prime} \mathrm{N} ; 119^{\circ} 7^{\prime} \mathrm{W} ; 260$ to $365 \mathrm{~m}$ asl). The soils are Burke silt loam and Warden silt loam of variable depth $>60 \mathrm{~cm}$. Certified, own-rooted Vitis vinifera L. winegrape cultivars (Chardonnay, Merlot, Pinot blanc, Pinot gris, Pinot noir, Sauvignon blanc, and Syrah) were planted in 2010, table grape cultivars (Flame Seedless and Summer Royal) were planted in 2005, and a juice grape cultivar (Concord, an interspecific hybrid with Vitis labrusca L. and V. vinifera ancestry) was planted in 1999. The plant spacing is $1.8 \mathrm{~m}$ within rows and $2.7 \mathrm{~m}$ between rows, which are oriented north-south on a $<2 \%$ south-facing slope. Wine and table grapes were trained to bilateral cordons at $0.9 \mathrm{~m}$ and spur pruned, with shoots positioned loosely between two pairs of foliage wires. Juice grapes were trained to bilateral cordons at $1.8 \mathrm{~m}$ and machine pruned, with shoots hanging freely. All other cultural practices were applied uniformly across cultivars, and no growth regulators were applied in any cultivar. Because annual precipitation at this site is only $\sim 200 \mathrm{~mm}$, the vineyards were drip-irrigated according to principles of regulated deficit irrigation. Irrigation water was applied between budbreak and bloom to avoid plant water stress, then water was withheld through mid-July to control shoot growth, followed by weekly irrigation with amounts depending on evaporative demand (replacing $\sim 65 \%$ of crop evapotranspiration) through harvest, after which water was applied to replenish soil water before winter. Daily weather data were obtained from an onsite AgWeatherNet station (http://weather.wsu.edu).

Stratified berry sampling method. This method relies on sampling grape berries based on tactile and visual cues, namely firmness to the touch and external color without rubbing off the epicuticular wax that gives many dark-skinned berries a blue appearance. Berries from dark-skinned cultivars were thus partitioned into homogenous categories that were classified as successive developmental stages as follows: green hard (GH), green soft (GS), blush/pink (BP), red/ purple (RP), and blue (B), irrespective of whether their mature skin color is considered to be "black," "gray," or "red" by the Vitis International Variety Catalogue (http:/www. vivc.de). Berries classified as GH and GS were green, without any signs of color change except for an occasional lighter green or slightly yellowish tinge of some GS berries. The GS berries were subjectively distinguished from GH berries by feeling soft when gently squeezed between thumb and index finger. Berries classified as BP either had variable-sized skin sections of pink and green or were completely pink, while berries classified as RP showed no evidence of greenness and appeared darker-colored than BP berries. Berries classified as B had completely changed color. The berries from white 
cultivars were classified into the developmental stages GH, GS, and yellow (Y). Berries classified as Y showed slightly translucent and yellowish skin. Because the berries could not be visually distinguished once they had completed their color change, we created two further categories based on total soluble solids (TSS): ripe (R: 20 to 24 Brix) and overripe (OR: $>24$ Brix).

In the studies described in the subsequent sections, sampling often started when at least some GS berries were present on the clusters, thus the GH berries were in the lag-phase of development. In a few instances, only GH berries were present when sampling started. In all cases, measurements of berry fresh weight (FW) and/or diameter and TSS were used to track berry development. Sampling usually continued until a sufficient number of berries had reached the OR stage. Berries were collected from randomly chosen clusters on main shoots in different positions of the canopy, including sun-exposed and shaded clusters, and from both sides of the canopy. Thus, whereas vines and clusters were chosen randomly, berries were grouped into developmental categories or stages based on firmness and color. When clusters contained berries of different stages on a sampling date, those berries were assigned to different categories. Conversely, when berries reached the same stage on different dates, they were pooled together into the same category.

Assessment of method robustness and reproducibility. Because grouping berries by touch and color alone might seem subjective, we examined the robustness and reproducibility of the stratified sampling method with respect to sampler (operator), cultivar, and environmental conditions. In a first test, five people were trained in 2014 to determine whether different operators can reliably and reproducibly classify berries using the stratified sampling method. Each person then collected Syrah berries of the developmental stages $\mathrm{GH}, \mathrm{GS}, \mathrm{BP}, \mathrm{RP}$, and B on a single day during veraison. The operators were instructed to randomly collect 10 berries for each of the five stages from random clusters across at least 20 vines. After independent categorization by each person, FW and TSS of each berry were measured as described below.

In a second test, 10 cultivars were sampled in 2014 to determine if the stratified sampling method can be used in different cultivars. We included seven winegrapes whose skin color is classified as "black" (Merlot, Pinot noir, Syrah), "gray" (Pinot gris), or "white" (Chardonnay, Pinot blanc, Sauvignon blanc), two seedless table grapes with "black" (Summer Royal) or "red" (Flame Seedless) skin color, and one juice grape (Concord) with "black" skin color (http://www.vivc.de). Using the sampling approach described above, 10 berries per stage per cultivar were collected between 13 Aug and 18 Sept. Depending on the cultivar, GH, GS, BP, and some RP and B berries were typically sampled on the same day and from the same clusters; other RP, B, and Y berries were sampled two weeks later; the remaining $\mathrm{B}$ and some $\mathrm{R}$ berries another week later; and the remaining $\mathrm{R}$ and $\mathrm{OR}$ berries over the final two weeks. Pinot noir, Pinot gris, Sauvignon blanc, and Flame Seedless did not reach the OR stage by harvest; Chardonnay was only sampled through to the Y stage; and Concord through the B stage. Diameter, FW, deformation, and TSS of each berry were measured as described below.

In a third test, Merlot and Syrah berries were sampled in 2014, 2015, and 2016 to determine if the stratified sampling method can be used regardless of environmental variation. To increase the potential variability due to environmental effects, samples were collected in different vineyard blocks in the different years. Berries were collected at the developmental stages GH, GS, BP, RP, B, R, and OR; sampling followed the same protocol as for the second test, except that berry numbers per stage were 10 in 2014, five to 15 in 2015, and 50 in 2016. Samples were collected approximately weekly from 13 Aug through 18 Sept in 2014, 13 July through 2 Oct in 2015, and 4 Aug through 12 Sept in 2016. Fresh weight and TSS of each berry were measured as described below.

Estimation of color change across fruit clusters. During 2014, 2015, and 2016, one sun-exposed cluster on the east side of the canopy was marked after fruit set on each of five Merlot and five Syrah vines in the vineyard. The clusters were photographed against a black cloth background with a digital camera (E-M5; Olympus) twice a week (weekly in 2016) between 0600 and $0700 \mathrm{hr}$ from fruit set to maturity. The camera lens (Olympus M. Zuiko Digital ED 12-50 mm, F3.5-6.3 EZ) was used in macro mode with the focal length fixed at $43 \mathrm{~mm}$, and the white balance was adjusted to compensate for changing light conditions. Direct sunlight was diffused using a semitransparent umbrella $\sim 1.5 \mathrm{~m}$ away from each cluster and with its axis pointing towards the sun. An example of an image series for a Merlot cluster is shown in Supplemental Figure 1. Ten berries were tracked visually on the images from each cluster to estimate the duration of the developmental stages GS, BP, RP, and B, which were distinguished as described in the Stratified berry sampling method section. The duration of a berry's GH phase was defined as the period from the average date of fruit set up until the change to GS. Additionally, the image sequence of five clusters was processed using ImageJ (Schneider et al. 2012) to quantify the color change over each cluster. Image brightness and contrast were adjusted automatically in ImageJ, and images were converted using the hue, saturation, brightness (HSB) stack transformation option. After binary conversion, white pixels represented green tissue and black pixels represented tissue that had changed color. The proportion of black pixels indicated the percentage color change relative to completely green clusters.

Detailed comparison of berry traits. During 2016, Merlot grape berries were sampled between the lag-phase and late ripening to study changes in physical and chemical attributes in more detail. Sampling started on 3 Aug for GH berries and continued at least twice weekly through 2 Sept for R berries, while OR berries were collected on 22 and 26 Sept. All berries were sampled between 0800 and $1000 \mathrm{hr}$ to minimize dehydration due to daytime transpiration (Keller et al. 2006, Zhang and Keller 2015). Two berries per cluster were sampled from approximately three clusters per vine from two to three vines per replicate for a total of at least 20 vines on each sampling date. There were 12 replicate samples for all 
developmental stages except OR, for which only eight samples were collected. Each sample comprised 12 to 15 berries of the same stage. The berries were classified into developmental categories using the stratified sampling method described above (on each date, we collected only berries belonging to a single stage) and placed in resealable plastic zipper bags (Ziploc) inside a portable cooler for immediate transport to the laboratory. Additional samples (six replicates of 50 berries each) were collected at each stage and stored at $-80^{\circ} \mathrm{C}$ for anthocyanin analysis. Because some 2016 samples were lost because of freezer malfunction, the anthocyanin analysis was repeated with samples collected in 2019. These data were pooled for analysis because the relationship between TSS and anthocyanins did not differ between the two years $\left(r^{2}=0.91\right.$ in 2016; $r^{2}=0.94$ in 2019).

Measurement of berry physical properties. Each berry was measured individually, and data were then averaged by sample replicate. The berries were weighed using a precision balance (AX205 DR, Mettler-Toledo). In 2014, berry diameter and deformation were measured using a skinfold caliper (British Indicators) as described in Chang et al. (2019). In 2015 and 2016, berry diameter and elastic modulus (E) were measured using a customized compression device described by Thomas et al. (2008). The compression device consisted of a linear actuator (21H4U-2.5-915, Haydon Kerk), load cell (FSH02664, Futek), microcontroller (Arduino Uno R3, Adafruit), and datalogger (Datalogging Arduino Shield, Adafruit). The measurement was done in two steps. First, the berry diameter was measured when the berry was engaged by the actuator and load cell at the same time. Second, the berry was squeezed slightly until the actuator had moved $1 \mathrm{~mm}$ or the force reached 0.1 N. Finally, E was calculated using the Hertz equation (Thomas et al. 2008). After these measurements were completed the pooled berries from each replicate were stored in resealable plastic zipper bags (Ziploc) at $-80^{\circ} \mathrm{C}$.

Measurement of berry chemical properties. Frozen berries were thawed overnight at room temperature, and juice was extracted manually by pressing the berries inside the plastic bags (Ziploc). The TSS concentration was analyzed using a benchtop refractometer (MT RE40D, Mettler-Toledo), and sugar content per berry was estimated from FW and TSS (Keller et al. 2016). TA was analyzed using an autotitrator (Titrino plus 848, Metrohm) connected to a compact sample changer (869 CSC, Metrohm). The $\mathrm{pH}$ was measured using an MP225 Quattro pH-meter (Mettler-Toledo). Malic acid (hereafter termed malate) and tartaric acid (hereafter termed tartrate) were determined in diluted juice using enzyme assay kits (K-LMAL and K-TART, Megazyme International), following manufacturer instructions, in a microplate spectrophotometer (SpectraMax Plus ${ }^{384}$, Molecular Devices). Organic acid contents per berry were estimated from concentrations and berry volume, which was estimated from FW and density. Density was estimated as described in Keller et al. (2015).

Total anthocyanins were measured using the method of Iland et al. (1996). Frozen berries were thawed overnight at $4^{\circ} \mathrm{C}$ and homogenized at $<10^{\circ} \mathrm{C}$ in a blender on high speed for $60 \mathrm{sec}$. Approximately $1 \mathrm{~g}$ of homogenate was transferred to a pre-tared centrifuge tube and weighed. Following the addition of $10 \mathrm{~mL}$ aqueous ethanol $(50 \% \mathrm{v} / \mathrm{v})$, the contents were mixed by inversion about every 10 min during a $1 \mathrm{hr}$ period. The tube was centrifuged at $1500 \mathrm{~g}$ for $7 \mathrm{~min}$, and the volume of the supernatant was measured. A $200-\mu \mathrm{L}$ aliquot of the extract was transferred to an acrylic cuvette $(10 \mathrm{~mm}$ path length), and $3.8 \mathrm{~mL}$ of $1.0-\mathrm{M} \mathrm{HCl}$ was added to acidify the extract to $\mathrm{pH} 1$. After incubating for $6 \mathrm{hr}$, anthocyanin concentration was determined spectrophotometrically at $520 \mathrm{~nm}$ (SpectraMax Plus ${ }^{384}$, Molecular Devices). Anthocyanin content per berry was estimated from berry FW, extract volume, and homogenate weight as described by Iland et al. (1996). Additionally, a subset of nine berries per sample was used to estimate the skin mass per area ratio (SMA) as a relative measure of skin thickness or density: 36 skin disks (four disks per berry) were collected using a cork borer ( $4 \mathrm{~mm}$ diam) and weighed. The SMA was determined as FW divided by area of the skin disks.

Statistical analysis. The effects of operator and developmental stage and their interaction in 2014 were analyzed by two-way analysis of variance (ANOVA) with stage as fixed factor and operator as random factor. The effect of developmental stage within each of 10 cultivars in 2014 was tested by one-way ANOVA, because we were interested here only in determining whether the stratified sampling method can be applied to different cultivars. The effect of cultivar, year, and developmental stage, and their interaction in the threeyear study with Merlot and Syrah was tested by three-way ANOVA with cultivar and stage as fixed factors and year as random factor. The effect of developmental stage in the 2016 Merlot study was tested by one-way ANOVA. Tukey's test was used for post-hoc means comparisons when the developmental stage effect was significant. Relationships between berry traits were tested using Pearson product moment correlation analysis. All data were analyzed using JMP 14.0 (SAS Institute). Box plots, correlation analysis, and curve fitting were made using SigmaPlot 12.0 (Systat Software).

\section{Results}

Method robustness and reproducibility. Five different people were able to identify and distinguish visually and by touch the stages GH, GS, BP, RP, and B. Each person sampled all berries for this test independently and on the same day from Syrah clusters that contained berries of all stages. The statistical analysis of the FW (Figure 2A) and TSS data (Figure 2B) showed no differences among individuals at the $\mathrm{GH}, \mathrm{BP}$, and B stages, and no interaction between operator and stage effects. Significant but minor differences among operators were observed only for the GS and RP stages. By contrast, for each person there were significant differences among most developmental stages. Although berry size and TSS were not used as sampling criteria, the sampling method generated three to four distinct berry FW classes (Figure 2A) and four to five distinct TSS classes (Figure 2B). This test for method robustness demonstrates that multiple developmental stages of berry ripening, all of which would normally be pooled together in a "veraison" sample, can be 
easily identified by different operators within individual fruit clusters based on firmness and color.

Table 1 shows the changes in FW, diameter, deformation, and TSS over the three to seven developmental stages that resulted from stratified sampling during and after veraison of berries from 10 cultivars of wine, table, and juice grapes varying in skin color at maturity from black to white. Despite the limited replication there was a significant, and often very marked, increase in each measured attribute as the berries of all cultivars softened and changed color. The TSS concentration increased from the GH to the OR stage, FW and diameter increased from the GH to the RP stage, and deformation upon compression generally increased strongly from the GH to the GS stage. Deformation in Pinot blanc, Pinot gris, Sauvignon blanc, Summer Royal, and Syrah berries continued to increase until harvest, whereas deformation decreased again in Concord berries from the RP to the B stage. Deformation measurements confirmed that the GH and GS categories were easily distinguished by touch in all cultivars but Summer Royal (Table 1). Although darker skin color permitted the berries that were changing color to be categorized into

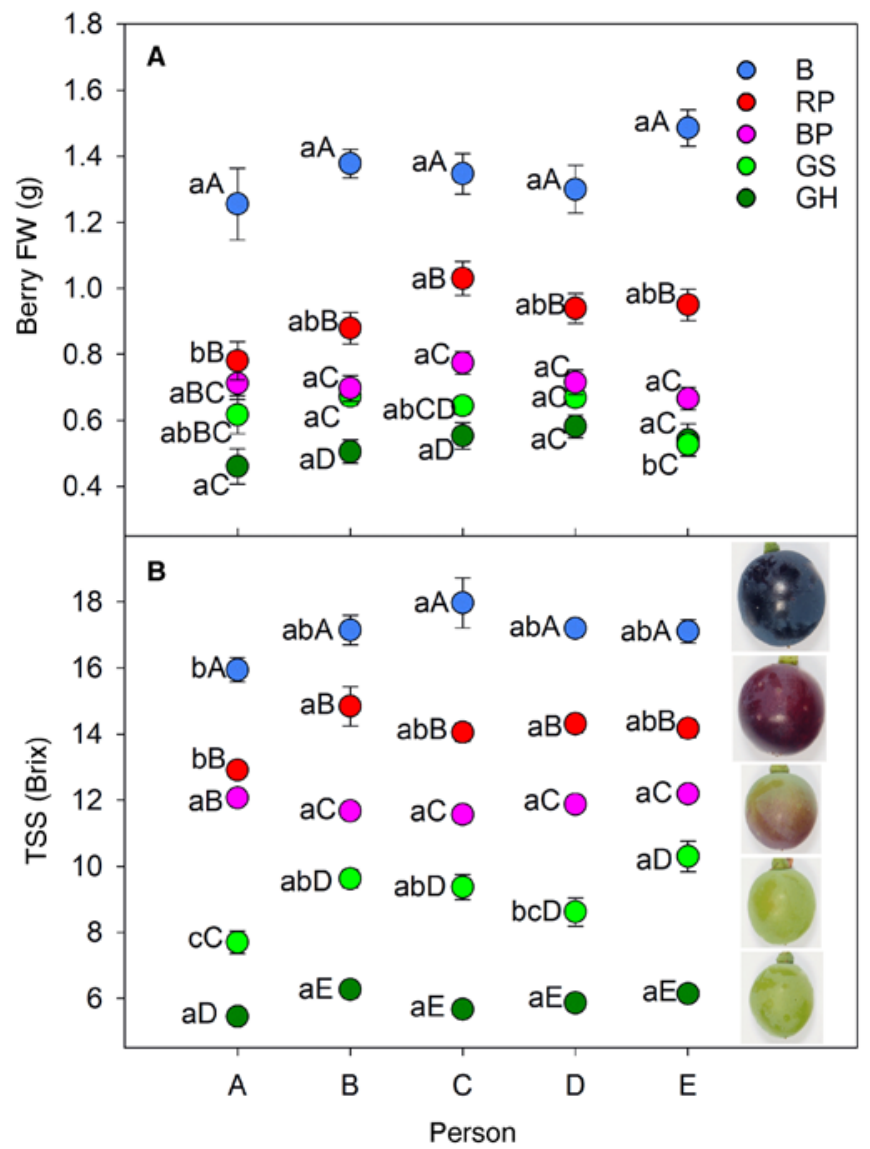

Figure 2 Changes in fresh weight (FW; A) and total soluble solids (TSS; B) across five developmental stages of Syrah grape berries in southeastern Washington in 2014. Berries were sampled according to their firmness to the touch and skin color ( $\mathrm{GH}=$ green hard; $\mathrm{GS}=$ green soft; $\mathrm{BP}=$ blush/ pink; RP = red/purple; B = blue) by five different people (A, B, C, D, E). Different uppercase letters denote significant differences among stages within each person; different lowercase letters denote significant differences among persons within each stage according to Tukey's test $(p<0.05$, $\mathrm{n}=10$ berries). Insets show typical berries at each sampled stage. more developmental stages, even Pinot gris berries could be assigned to BP, RP, and B, whereas these three categories were lumped into a single $\mathrm{Y}$ stage in white-skinned cultivars. These results confirmed that the stratified sampling method is reproducible across a diverse spectrum of grape cultivars.

When Merlot and Syrah berries were sampled over three years, all effects on FW and TSS and all interactions except cultivar $\times$ year for FW $(p=0.02)$ and TSS $(p=0.12)$ were significant at $p<0.001$. There were strong correlations between berry FW and TSS each year (Figure 3 ). The slopes and intercepts of the regression lines varied among years and between the two cultivars as a result of genotype $\times$ environment interactions. Whereas berry size increased in Merlot throughout ripening, Syrah berries showed the late-season weight loss typical for this cultivar in two out of three years. However, the developmental categories were maintained and clearly separated in all cases, indicating that the stratified sampling method is robust and reproducible with respect to environmental variation.

Color change across fruit clusters. Sequential image analysis of photographs of five Merlot clusters showed that color change of the berries extended over 20 to 30 days across each individual cluster (Figure 1). The first and the last cluster started and completed color change 10 days apart and reached the level of 50\% color change seven days apart. Tracing individual Merlot and Syrah berries visually over time permitted an estimation of the duration of developmental stages during veraison (Table 2). Berry softening (i.e., GH to GS transition) occurred $\sim 6$ Aug, 21 July, and 29 July in 2014, 2015, and 2016, respectively, and color change began about three to four days later. On average, the berries took between 11 and 14 days to transition from GS to B, and between eight and 10 days to complete their color change once initiated (i.e., BP to B transition). Although 2016 was the coolest of the three growing seasons, all three were substantially warmer than the long-term average (Table 3). While the onset of berry softening occurred earlier during the hot 2015 season, this was not associated with a more rapid transition from GS to B, perhaps because hot days during this period were balanced by cool nights in 2015 (Table 3). In both cultivars, the duration of the GS to B transition was longer during the cooler 2016 season (Table 2), even though only the earlier Merlot experienced cooler temperatures during veraison (Table 3).

Grape berry physical properties. The extensive sampling campaign conducted in 2016 showed that Merlot berry FW almost doubled ( $+88 \%$ ) between the GH and OR stages (Figure 4A). There was a marked increase in berry size from the GH to the GS stage, which was also evident in the correlation between TSS and FW (Figure 5A), while E dropped 83\% from GH to GS and then remained almost constant (Figure 4B). The relationship between TSS and E was best described by an exponential decay function, with almost all of the developmental change in E occurring between GH and GS (Figure 5B). Similar decay functions also described the relationships between sugar content (amount per berry) and E (Figure 6A) and between FW and E (Figure 6B). Although E was much more variable in $\mathrm{GH}$ berries than in all subsequent stages, 
142 - Hernández-Montes et al.

Table 1 Grape berry physical properties and total soluble solids (TSS) across three to seven developmental stages (GH = green hard; GS = green soft; $B P=$ blush/pink; $R P=$ red/purple; $B=$ blue; $R=$ ripe; OR = overripe; $Y=$ yellow) in different wine, table, and juice grape cultivars in southeastern Washington in 2014. Values are means of 10 ( $\geq 5$ for OR) berries \pm SE. FW, fresh weight.

\begin{tabular}{|c|c|c|c|c|c|}
\hline Cultivar / type & Stage & Berry FW (g) & Diameter $(\mathrm{mm})$ & Deformation (\%) & TSS (Brix) \\
\hline \multirow[t]{7}{*}{ Merlot / black winegrape } & $\mathrm{GH}$ & $0.59 \pm 0.03 \mathrm{e}^{\mathrm{a}}$ & $10.0 \pm 0.2 \mathrm{~d}$ & $3.8 \pm 0.4 b$ & $5.1 \pm 0.2 \mathrm{~g}$ \\
\hline & GS & $0.71 \pm 0.04 \mathrm{de}$ & $10.9 \pm 0.2 \mathrm{~cd}$ & $8.9 \pm 0.4 a$ & $8.0 \pm 0.8 f$ \\
\hline & $\mathrm{BP}$ & $0.90 \pm 0.05 \mathrm{de}$ & $11.6 \pm 0.2 c$ & $8.2 \pm 0.3 a$ & $11.6 \pm 0.2 \mathrm{e}$ \\
\hline & $\mathrm{RP}$ & $1.21 \pm 0.06 \mathrm{c}$ & $12.7 \pm 0.2 b$ & $8.4 \pm 0.4 \mathrm{a}$ & $16.5 \pm 0.6 \mathrm{~d}$ \\
\hline & B & $1.38 \pm 0.07 b c$ & $13.1 \pm 0.2 \mathrm{ab}$ & $9.0 \pm 0.4 \mathrm{a}$ & $18.7 \pm 0.2 c$ \\
\hline & $\mathrm{R}$ & $1.49 \pm 0.05 a b$ & $13.5 \pm 0.2 \mathrm{ab}$ & $9.9 \pm 0.5 \mathrm{a}$ & $21.4 \pm 0.3 b$ \\
\hline & OR & $1.67 \pm 0.06 \mathrm{a}$ & $13.8 \pm 0.2 \mathrm{a}$ & $8.7 \pm 0.3 a$ & $24.9 \pm 0.3 a$ \\
\hline \multirow[t]{7}{*}{ Syrah / black winegrape } & $\mathrm{GH}$ & $0.99 \pm 0.07 b$ & $11.3 \pm 0.3 b$ & $3.9 \pm 0.3 \mathrm{e}$ & $4.9 \pm 0.4 f$ \\
\hline & GS & $1.03 \pm 0.05 b$ & $11.5 \pm 0.2 b$ & $7.2 \pm 0.6 \mathrm{~d}$ & $7.3 \pm 0.4 f$ \\
\hline & BP & $1.00 \pm 0.06 b$ & $11.5 \pm 0.3 b$ & $8.4 \pm 0.5 \mathrm{~cd}$ & $11.0 \pm 0.4 \mathrm{e}$ \\
\hline & $\mathrm{RP}$ & $1.57 \pm 0.05 \mathrm{a}$ & $13.6 \pm 0.2 \mathrm{a}$ & $9.1 \pm 0.3 \mathrm{~cd}$ & $14.2 \pm 0.6 \mathrm{~d}$ \\
\hline & $\mathrm{B}$ & $1.79 \pm 0.05 a$ & $13.9 \pm 0.1 \mathrm{a}$ & $10.1 \pm 0.4 \mathrm{bc}$ & $18.3 \pm 0.4 c$ \\
\hline & $\mathrm{R}$ & $1.64 \pm 0.06 a$ & $13.5 \pm 0.2 \mathrm{a}$ & $11.5 \pm 0.5 a b$ & $21.4 \pm 0.5 b$ \\
\hline & OR & $1.61 \pm 0.11 \mathrm{a}$ & $13.1 \pm 0.3 \mathrm{a}$ & $12.8 \pm 0.8 \mathrm{a}$ & $25.0 \pm 0.4 \mathrm{a}$ \\
\hline \multirow[t]{6}{*}{ Pinot noir / black winegrape } & $\mathrm{GH}$ & $0.51 \pm 0.02 \mathrm{~d}$ & $9.5 \pm 0.2 c$ & $3.4 \pm 0.3 b$ & $6.1 \pm 0.2 \mathrm{e}$ \\
\hline & GS & $0.94 \pm 0.05 c$ & $11.6 \pm 0.2 b$ & $6.6 \pm 0.5 \mathrm{a}$ & $9.7 \pm 0.7 \mathrm{~d}$ \\
\hline & $\mathrm{BP}$ & $0.90 \pm 0.04 c$ & $11.4 \pm 0.2 b$ & $7.2 \pm 0.3 a$ & $12.8 \pm 0.3 c$ \\
\hline & $\mathrm{RP}$ & $1.49 \pm 0.06 b$ & $13.5 \pm 0.2 \mathrm{a}$ & $7.4 \pm 0.3 a$ & $17.0 \pm 0.3 b$ \\
\hline & $B$ & $1.69 \pm 0.05 a$ & $14.0 \pm 0.2 \mathrm{a}$ & $7.4 \pm 0.4 \mathrm{a}$ & $17.8 \pm 0.5 b$ \\
\hline & $\mathrm{R}$ & $1.52 \pm 0.08 \mathrm{ab}$ & $13.4 \pm 0.1 \mathrm{a}$ & $6.8 \pm 0.4 a$ & $20.6 \pm 0.2 \mathrm{a}$ \\
\hline \multirow[t]{6}{*}{ Pinot gris / gray winegrape } & $\mathrm{GH}$ & $0.42 \pm 0.03 \mathrm{e}$ & $8.6 \pm 0.2 \mathrm{e}$ & $3.1 \pm 0.3 d$ & $5.9 \pm 0.2 \mathrm{e}$ \\
\hline & GS & $0.77 \pm 0.04 \mathrm{~d}$ & $10.5 \pm 0.2 \mathrm{~d}$ & $6.5 \pm 0.3 c$ & $9.5 \pm 0.6 \mathrm{~d}$ \\
\hline & BP & $0.97 \pm 0.03 c$ & $11.4 \pm 0.1 c$ & $7.2 \pm 0.4 c$ & $14.4 \pm 0.5 c$ \\
\hline & $\mathrm{RP}$ & $1.27 \pm 0.07 b$ & $12.5 \pm 0.2 b$ & $8.9 \pm 0.4 b$ & $18.0 \pm 0.3 b$ \\
\hline & $B$ & $1.67 \pm 0.09 \mathrm{a}$ & $13.8 \pm 0.3 a$ & $11.0 \pm 0.6 \mathrm{a}$ & $19.0 \pm 0.3 b$ \\
\hline & $\mathrm{R}$ & $1.67 \pm 0.09 a$ & $13.6 \pm 0.3 a$ & $10.2 \pm 0.5 \mathrm{ab}$ & $22.3 \pm 0.4 \mathrm{a}$ \\
\hline \multirow[t]{5}{*}{ Pinot blanc / white winegrape } & $\mathrm{GH}$ & $0.52 \pm 0.04 c$ & $9.3 \pm 0.3 c$ & $3.1 \pm 0.3 c$ & $5.3 \pm 0.2 \mathrm{e}$ \\
\hline & GS & $0.93 \pm 0.05 b$ & $11.3 \pm 0.2 b$ & $7.5 \pm 0.7 b$ & $11.4 \pm 1.0 \mathrm{~d}$ \\
\hline & $\mathrm{Y}$ & $1.64 \pm 0.08 \mathrm{a}$ & $13.8 \pm 0.3 a$ & $9.6 \pm 0.5 b$ & $17.9 \pm 0.5 c$ \\
\hline & $\mathrm{R}$ & $1.81 \pm 0.14 \mathrm{a}$ & $14.0 \pm 0.4 \mathrm{a}$ & $9.6 \pm 0.7 b$ & $21.6 \pm 0.3 b$ \\
\hline & OR & $1.68 \pm 0.09 a$ & $13.5 \pm 0.3 a$ & $13.3 \pm 0.9 a$ & $25.4 \pm 0.3 a$ \\
\hline \multirow[t]{3}{*}{ Chardonnay / white winegrape } & $\mathrm{GH}$ & $0.51 \pm 0.05 c$ & $9.5 \pm 0.3 c$ & $4.3 \pm 0.5 b$ & $5.9 \pm 0.2 c$ \\
\hline & GS & $0.75 \pm 0.04 b$ & $10.8 \pm 0.2 b$ & $11.7 \pm 0.7 \mathrm{a}$ & $10.6 \pm 0.3 b$ \\
\hline & Y & $1.06 \pm 0.05 \mathrm{a}$ & $12.0 \pm 0.2 \mathrm{a}$ & $12.0 \pm 0.4 \mathrm{a}$ & $17.6 \pm 0.6 \mathrm{a}$ \\
\hline \multirow[t]{4}{*}{ Sauvignon blanc/white winegrape } & $\mathrm{GH}$ & $0.36 \pm 0.04 c$ & $8.3 \pm 0.3 c$ & $2.8 \pm 0.3 c$ & $6.3 \pm 0.4 \mathrm{~d}$ \\
\hline & GS & $0.73 \pm 0.06 b$ & $10.5 \pm 0.3 b$ & $7.9 \pm 0.9 b$ & $12.0 \pm 0.9 c$ \\
\hline & $\mathrm{Y}$ & $1.21 \pm 0.06 \mathrm{a}$ & $12.3 \pm 0.2 \mathrm{a}$ & $8.1 \pm 0.4 b$ & $17.1 \pm 0.6 b$ \\
\hline & $\mathrm{R}$ & $1.35 \pm 0.06 \mathrm{a}$ & $12.7 \pm 0.2 \mathrm{a}$ & $10.9 \pm 0.5 \mathrm{a}$ & $22.2 \pm 0.2 \mathrm{a}$ \\
\hline \multirow[t]{5}{*}{ Flame Seedless / red table grape } & $\mathrm{GH}$ & $0.79 \pm 0.05 d$ & $11.1 \pm 0.2 b$ & $1.7 \pm 0.4 b$ & $4.6 \pm 0.3 \mathrm{e}$ \\
\hline & GS & $1.08 \pm 0.05 \mathrm{~cd}$ & $12.4 \pm 0.2 b$ & $4.2 \pm 0.8 a$ & $9.5 \pm 1.1 \mathrm{~d}$ \\
\hline & $\mathrm{BP}$ & $1.65 \pm 0.07 \mathrm{bc}$ & $14.2 \pm 0.2 \mathrm{a}$ & $5.4 \pm 0.6 a$ & $13.1 \pm 0.6 c$ \\
\hline & RP & $1.95 \pm 0.20 \mathrm{ab}$ & $14.9 \pm 0.5 \mathrm{a}$ & $6.1 \pm 0.5 a$ & $18.5 \pm 0.3 b$ \\
\hline & $\mathrm{R}$ & $2.39 \pm 0.28 \mathrm{a}$ & $15.7 \pm 0.7 \mathrm{a}$ & $4.4 \pm 0.5 a$ & $21.1 \pm 0.3 a$ \\
\hline \multirow[t]{7}{*}{ Summer Royal / black table grape } & $\mathrm{GH}$ & $0.90 \pm 0.07 \mathrm{~d}$ & $11.5 \pm 0.3 \mathrm{~d}$ & $1.4 \pm 0.2 \mathrm{e}$ & $6.3 \pm 0.4 f$ \\
\hline & GS & $1.20 \pm 0.07 \mathrm{~d}$ & $12.7 \pm 0.2 \mathrm{~d}$ & $2.8 \pm 0.3 \mathrm{de}$ & $8.1 \pm 0.3 \mathrm{ef}$ \\
\hline & $\mathrm{BP}$ & $1.82 \pm 0.07 c$ & $14.7 \pm 0.2 c$ & $3.9 \pm 0.4 \mathrm{~cd}$ & $10.7 \pm 0.4 \mathrm{e}$ \\
\hline & $\mathrm{RP}$ & $2.26 \pm 0.06 c$ & $15.5 \pm 0.2 b c$ & $5.5 \pm 0.3 b c$ & $13.6 \pm 0.3 d$ \\
\hline & $\mathrm{B}$ & $2.98 \pm 0.17 b$ & $17.1 \pm 0.4 \mathrm{a}$ & $4.9 \pm 0.3 b c$ & $17.6 \pm 0.7 \mathrm{c}$ \\
\hline & $\mathrm{R}$ & $3.50 \pm 0.11 \mathrm{a}$ & $17.5 \pm 0.2 \mathrm{a}$ & $6.1 \pm 0.5 a b$ & $22.1 \pm 0.3 b$ \\
\hline & OR & $3.00 \pm 0.09 a b$ & $16.2 \pm 0.1 \mathrm{ab}$ & $7.7 \pm 0.2 \mathrm{a}$ & $25.5 \pm 0.3 a$ \\
\hline \multirow[t]{5}{*}{ Concord / black juice grape } & $\mathrm{GH}$ & $1.56 \pm 0.07 c$ & $13.9 \pm 0.2 b$ & $2.8 \pm 0.2 c$ & $6.1 \pm 0.1 \mathrm{~d}$ \\
\hline & GS & $1.63 \pm 0.09 c$ & $13.7 \pm 0.3 b$ & $6.5 \pm 0.4 \mathrm{a}$ & $7.9 \pm 0.4 \mathrm{c}$ \\
\hline & $\mathrm{BP}$ & $1.67 \pm 0.11 \mathrm{bc}$ & $13.8 \pm 0.3 b$ & $6.6 \pm 0.2 \mathrm{a}$ & $9.2 \pm 0.1 \mathrm{c}$ \\
\hline & $\mathrm{RP}$ & $1.94 \pm 0.06 \mathrm{~b}$ & $14.5 \pm 0.1 \mathrm{~b}$ & $6.8 \pm 0.2 \mathrm{a}$ & $12.4 \pm 0.4 b$ \\
\hline & $\mathrm{B}$ & $2.73 \pm 0.06 \mathrm{a}$ & $16.3 \pm 0.1 \mathrm{a}$ & $5.2 \pm 0.2 b$ & $15.5 \pm 0.4 a$ \\
\hline
\end{tabular}

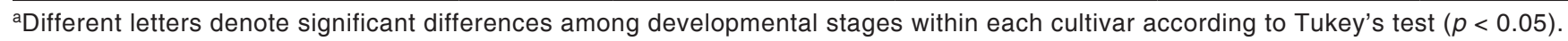


there was no correlation with sugar content within GH berries $\left(\mathrm{r}^{2}=0.02, p=0.97\right)$, suggesting that much of the drop in $\mathrm{E}$ occurred before sugars began to accumulate. Similarly, the lack of correlation within GH berries between $\mathrm{E}$ and $\mathrm{FW}\left(\mathrm{r}^{2}\right.$ $=0.21, p=0.15$ ) suggests that softening also occurred mostly before the resumption of berry expansion. As berry size increased, so did the weight of the skin per unit surface area as demonstrated by the correlation between berry FW and SMA

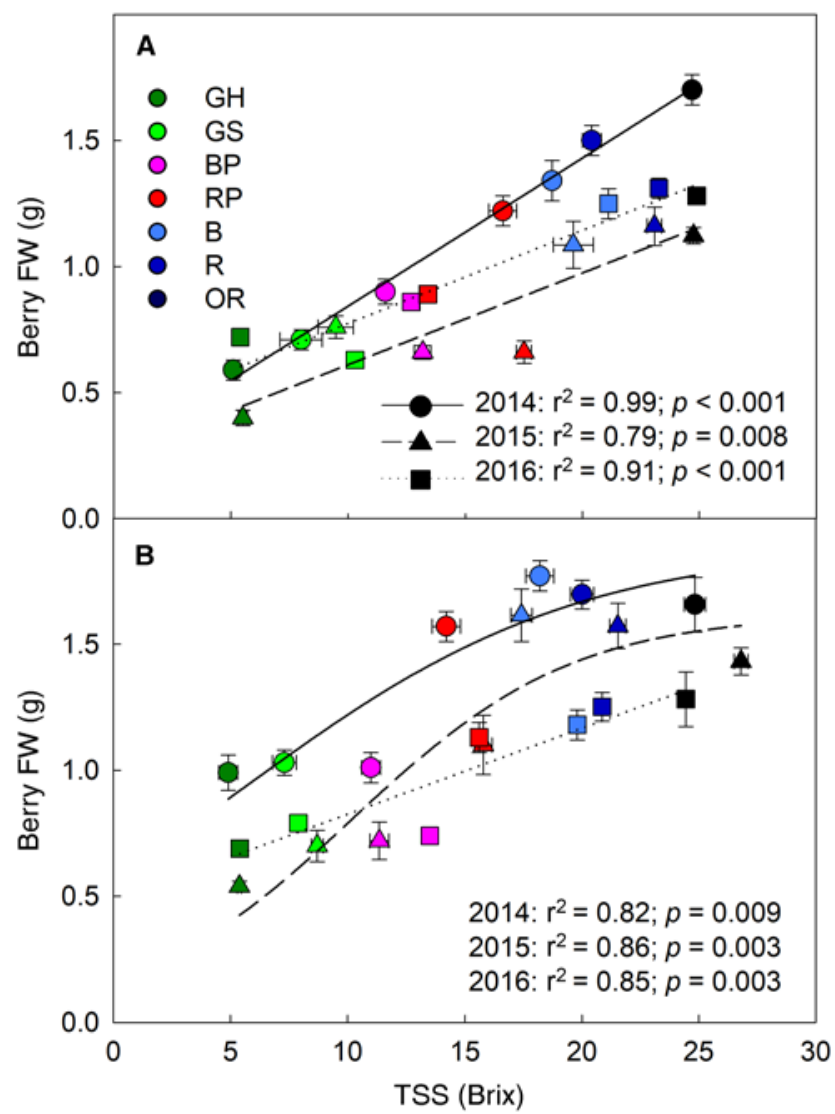

Figure 3 Relationship between total soluble solids (TSS) and fresh weight (FW) across seven developmental stages $(\mathrm{GH}=$ green hard; $\mathrm{GS}=$ green soft; $B P=$ blush/pink; $R P=$ red/purple; $B=$ blue; $R=$ ripe; $O R=$ overripe) of Merlot (A) and Syrah (B) grape berries in southeastern Washington over three years. Values are means \pm SE of 10 berries in 2014, five to 15 berries in 2015, and 50 berries in 2016 .
(Figure 7). Similarly, there was a positive correlation between TSS and SMA $\left(\mathrm{r}^{2}=0.56, p<0.001\right)$. However, the variation in SMA also increased with increasing berry weight and TSS.

Grape berry chemical properties. The TSS (Figure 8A) and sugar content per berry (Figure 9A) steadily increased in Merlot berries from the GH stage to the OR stage, showing significant differences among successive developmental stages. The average sugar content of OR berries was 22 -fold greater than that of GH berries. Moreover, GH berries contained higher amounts of organic acids than sugars, but this was reversed from GS berries onward because of the simultaneous and rapid sugar accumulation and malate degradation (Figure 9A and 9C). The TA concentration and content decreased from the GH stage until the berries turned blue; thereafter, no significant differences were found among B, $\mathrm{R}$, and $\mathrm{OR}$ berries (Figures $8 \mathrm{~B}$ and $9 \mathrm{~B}$ ). There was a strong and almost linear relationship between TSS and TA when TA was expressed as either concentration (Figure 10A) or content (Figure 10B). Malate concentration and content had similar developmental trends as TA (Figure 10C and 10D), indicating that the decrease in TA was driven by the decrease in malate. Indeed, the variation in malate content throughout berry ripening accounted for $90 \%$ of the variation in TA (Figure 11), whereas tartrate accounted for only $21 \%$ of the variation in TA. Malate was degraded as the berries changed from $\mathrm{GH}$ to B with no further change thereafter (Figure 8C). The relationships between TSS and malate concentration and content followed exponential decay functions, leveling off above 17 Brix (Figure 10C and 10D). In stark contrast with malate, there was no clear developmental trend in tartrate concentration (Figure 8D) or content (Figure 9D). While malate was the major organic acid in GH to BP berries, the metabolically stable tartrate assumed this role in B to OR berries; the two acids were briefly balanced at the RP stage.

The $\mathrm{pH}$ increased from $\sim 2.7$ in $\mathrm{GH}$ berries to 3.5 in $\mathrm{B}$ berries, and stabilized thereafter (Figure 8E), mirroring the changes in TA and malate. The pH correlated well with TSS (Figure 10E), TA (Figure 12), and malate (Figure 11B) during ripening. Compared with malate, however, the $\mathrm{pH}$ was less variable in GH to RP berries and more variable in $\mathrm{B}$, R, and OR berries. Moreover, unlike malate, the $\mathrm{pH}$ correlated with

Table 2 Duration of developmental stages $(\mathrm{GH}=$ green hard; $\mathrm{GS}=$ green soft; $\mathrm{BP}=$ blush/pink; $\mathrm{RP}=$ red/purple; $\mathrm{B}=\mathrm{blue})$, distinguished visually and by touch, after fruit set of Merlot and Syrah grape berries in southeastern Washington over three years (DOY $=$ day of year). Values are means of 50 berries \pm SE.

\begin{tabular}{|c|c|c|c|c|c|c|c|}
\hline Cultivar/year & $\begin{array}{l}\text { Fruit set } \\
\text { (DOY) }\end{array}$ & $\mathrm{GH}^{\mathrm{a}}$ (days) & GS (days) & BP (days) & RP (days) & GS-B (days) & BP-B (days) \\
\hline \multicolumn{8}{|l|}{ Merlot } \\
\hline 2014 & 170 & $48.6 \pm 1.0$ & $3.5 \pm 0.2$ & $3.5 \pm 0.2$ & $4.7 \pm 0.2$ & $11.6 \pm 0.3$ & $8.1 \pm 0.3$ \\
\hline 2015 & 153 & $51.4 \pm 0.4$ & $3.3 \pm 0.1$ & $4.0 \pm 0.2$ & $4.9 \pm 0.2$ & $12.2 \pm 0.3$ & $8.9 \pm 0.3$ \\
\hline 2016 & 159 & $52.2 \pm 0.5$ & $3.3 \pm 0.1$ & $4.3 \pm 0.2$ & $5.2 \pm 0.2$ & $12.8 \pm 0.3$ & $9.6 \pm 0.3$ \\
\hline \multicolumn{8}{|l|}{ Syrah } \\
\hline 2014 & 170 & $48.4 \pm 0.8$ & $4.2 \pm 0.2$ & $2.8 \pm 0.2$ & $4.0 \pm 0.2$ & $11.0 \pm 0.4$ & $6.8 \pm 0.2$ \\
\hline 2015 & 156 & $45.8 \pm 0.4$ & $4.4 \pm 0.1$ & $3.6 \pm 0.2$ & $4.0 \pm 0.2$ & $12.1 \pm 0.3$ & $7.6 \pm 0.2$ \\
\hline 2016 & 155 & $61.2 \pm 0.9$ & $4.4 \pm 0.2$ & $4.2 \pm 0.3$ & $5.8 \pm 0.2$ & $14.4 \pm 0.4$ & $10.1 \pm 0.4$ \\
\hline
\end{tabular}

aThe duration of the GH phase is defined here as the period from fruit set to berry softening, but GH berries for analysis of physical and chemical traits were sampled during late lag-phase. 
TSS over the entire TSS range from 5 to 25 Brix. These results indicate that the $\mathrm{pH}$ became less buffered as the berries matured, and some changes in $\mathrm{pH}$ occurred independently of malate in mature berries. Nevertheless, the overall variation in TA accounted for $95 \%$ of the variation in $\mathrm{pH}$ (Figure 12), and the variation in malate explained $89 \%$ of the variation in $\mathrm{pH}$ (Figure 11B).

Skin color changes were identified visually. To confirm that the visual perception corresponded with anthocyanin accumulation, anthocyanins were quantified at each developmental stage of Merlot berries. Anthocyanins were not found in GH and GS berries; they began to accumulate in $\mathrm{BP}$ berries, followed by a rapid increase through the R stage (Figure 8F). Both the anthocyanin concentration and its content correlated well with TSS above 10 Brix (no anthocyanins were found below 10 Brix), following an exponential growth function until the berries turned blue, and then beginning to flatten above 17 Brix. However, the variation in anthocyanin concentration and content increased considerably as the berries matured, indicating that anthocyanin accumulation was initially tightly coupled to sugar accumulation but was driven by factors other than sugar supply beyond the B stage.

\section{Discussion}

The present study demonstrated that sampling grape berries by firmness to the touch and visible skin color is a reliable and robust method to overcome the apparent constraints inherent in the developmental heterogeneity of berries within clusters when studying physical, chemical, physiological, and molecular changes that occur at the onset of ripening. The stratified sampling method subdivides berries that would normally be lumped into a single "veraison" sample into several developmental stages in both seeded wine and juice grape cultivars and seedless table grape cultivars. Although darker skin color due to anthocyanin accumulation permitted berries to be categorized into more developmental stages while they were undergoing color change, the method was successfully applied to cultivars with black, red, gray, and

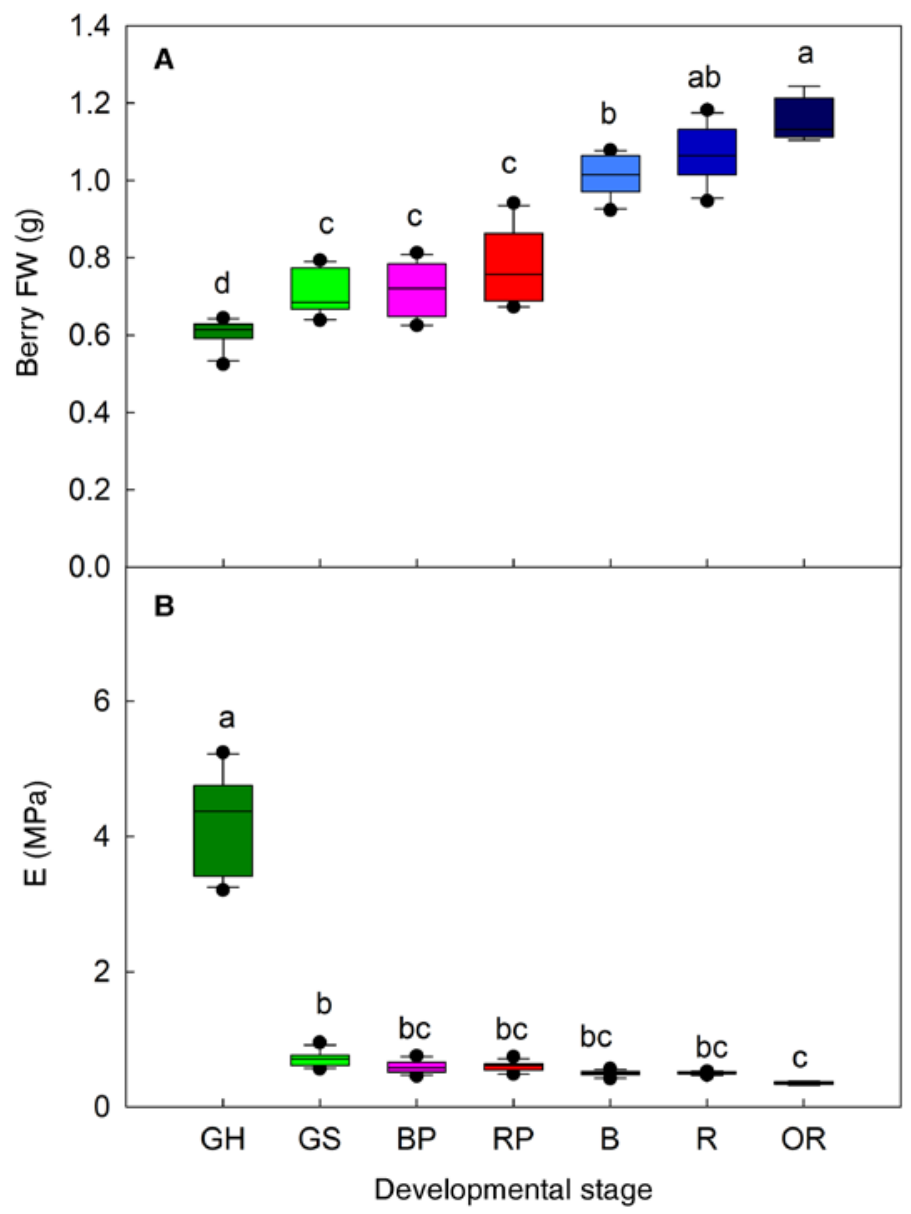

Figure 4 Changes in fresh weight (FW; A) and elastic modulus (E; B) across seven developmental stages $(\mathrm{GH}=$ green hard; $\mathrm{GS}=$ green soft; $\mathrm{BP}=$ blush/pink; RP = red/purple; $\mathrm{B}=$ blue; $\mathrm{R}=$ ripe; $\mathrm{OR}=$ overripe) of Merlot grape berries in southeastern Washington in 2016. The central line in each box plot indicates the median, box boundaries indicate the 25th and 75th percentiles, whiskers indicate the 10th and 90th percentiles, black circles represent outliers outside the 5th and 95th percentiles. Different letters indicate significant differences among developmental stages according to Tukey's test $(p<0.05, \mathrm{n}=12$ samples of 12 to 15 berries each).

Table 3 Summary of temperature conditions at the Irrigated Agriculture Research and Extension Center in southeastern Washington during three growing seasons. Data were collected by a local AgWeatherNet station. All data except growing degree days (GDD) apply to the average period of the green soft to blue transition (GS-B) of 50 separate Merlot and Syrah berries, as shown in Table 2.

\begin{tabular}{|c|c|c|c|c|c|c|c|c|}
\hline \multirow[b]{2}{*}{ Cultivar/year } & \multirow[b]{2}{*}{$\mathrm{GDD}^{\mathrm{c}}\left({ }^{\circ} \mathrm{C}\right)$} & \multirow[b]{2}{*}{$\mathbf{T}_{\text {mean }}{ }^{d}\left({ }^{\circ} \mathbf{C}\right)$} & \multirow[b]{2}{*}{ Trange $^{\mathrm{e}}\left({ }^{\circ} \mathrm{C}\right)$} & \multicolumn{3}{|c|}{$\mathbf{T}_{\max }$ days $^{a}$} & \multicolumn{2}{|c|}{$T_{\min }$ days $^{b}$} \\
\hline & & & & $>40^{\circ} \mathrm{C}$ & $>35^{\circ} \mathrm{C}$ & $>30^{\circ} \mathrm{C}$ & $<15^{\circ} \mathrm{C}$ & $<10^{\circ} \mathrm{C}$ \\
\hline \multicolumn{9}{|l|}{ Merlot } \\
\hline 2014 & 1719 & 23.9 & 17.2 & 0 & 3 & 11 & 5 & 0 \\
\hline 2015 & 1755 & 23.1 & 19.8 & 2 & 4 & 8 & 9 & 3 \\
\hline 2016 & 1568 & 21.8 & 18.2 & 0 & 2 & 7 & 10 & 1 \\
\hline \multicolumn{9}{|l|}{ Syrah } \\
\hline 2014 & & 23.6 & 17.5 & 0 & 3 & 9 & 6 & 0 \\
\hline 2015 & & 22.3 & 19.8 & 2 & 3 & 7 & 11 & 2 \\
\hline 2016 & & 22.3 & 19.2 & 0 & 4 & 9 & 11 & 1 \\
\hline
\end{tabular}

${ }^{a}$ Number of days during GS-B with maximum temperatures above three threshold temperatures.

${ }^{b}$ Number of days during GS-B with minimum temperatures below two threshold temperatures.

${ }^{\circ}$ Cumulative growing degree days $\left(>10^{\circ} \mathrm{C}\right)$ from 1 April to 31 Oct (long-term GDD = 1451).

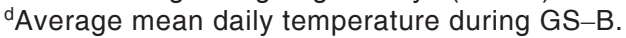

${ }^{e}$ Average daily temperature range during GS-B. 
white skin at maturity. We showed that berries of the GH, GS, BP, RP, and B stages were easily distinguished by different people and in different cultivars, years, and locations. Of course, color change occurs along a continuum, and with additional training the BP and RP categories could be further subdivided into blush, pink, red, and purple (Keller et al.

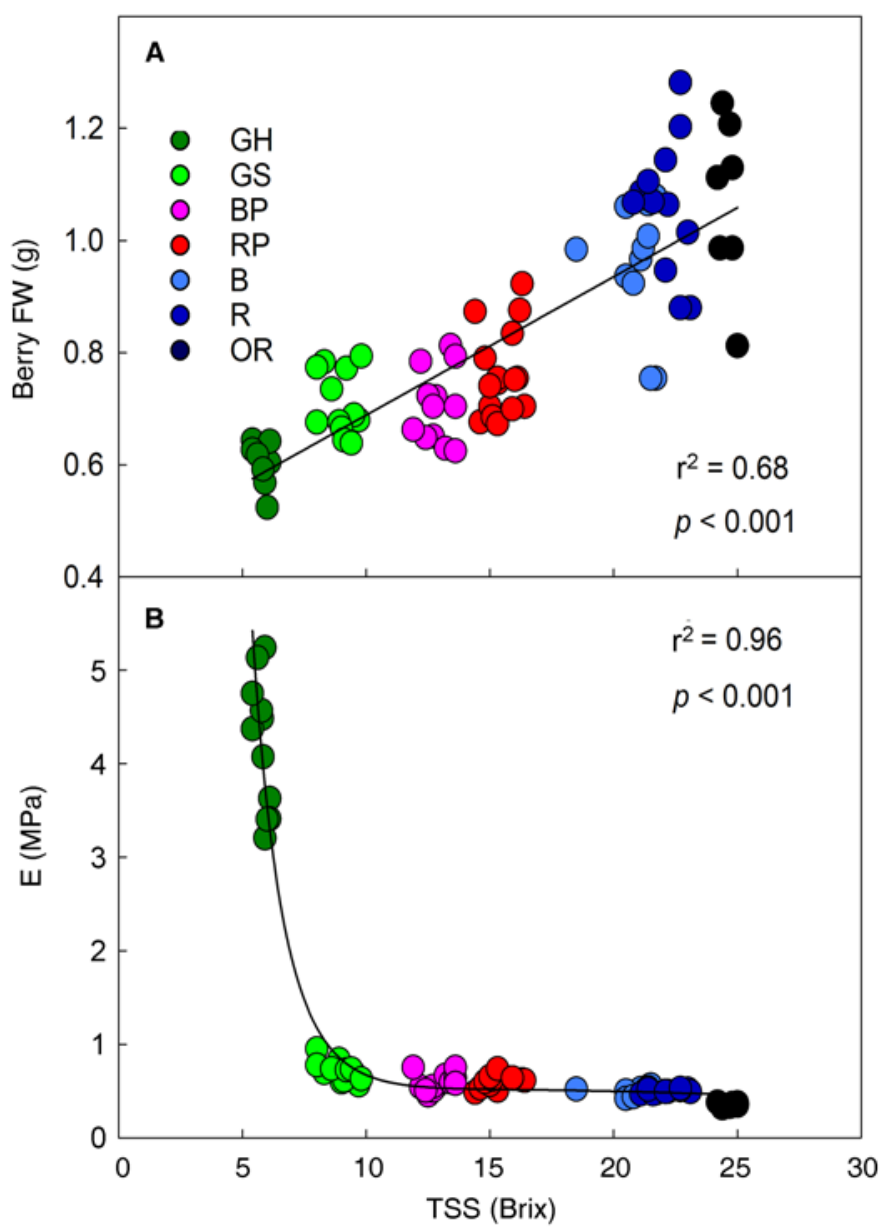

Figure 5 Relationship between total soluble solids (TSS) and fresh weight (FW; A) and elastic modulus (E; B) across seven developmental stages $(\mathrm{GH}=$ green hard; $\mathrm{GS}=$ green soft; $\mathrm{BP}=$ blush/pink; RP = red/purple; $\mathrm{B}$ = blue; $\mathrm{R}=$ ripe; $\mathrm{OR}=$ overripe) of Merlot grape berries in southeastern Washington in 2016. Each symbol represents a sample of 12 to 15 berries.
2006). Moreover, all measures of grape maturity analyzed here correlated closely with TSS, especially during the early ripening phase.

Coombe (1992) asserted that the term "veraison" describes the many changes that occur in a grape berry at the inception of ripening, but our results suggest that this is an imprecise definition that may have hindered progress in grape ripening research. In agreement with Coombe (1992), our data show that individual berries in a grape cluster enter the ripening phase at different times, leading to the co-occurrence of developmentally distinct berries at the phenological stage of veraison. The percentage of berries in a cluster that started changing color from green to blue increased from 0 to $38 \%$ in 15 days and then to $100 \%$ in only nine days in our study. However, as a berry undergoes color change, it not only accumulates anthocyanins but also softens (10-fold change in E from GH to R: $>5$ to $0.5 \mathrm{MPa}$ ) and accumulates sugars (three-fold change in TSS from GH to R: 5 to $>15$ Brix) while reducing its acidity (five-fold change in TA from GH to R: 25 to $5 \mathrm{~g} / \mathrm{L}$ ). Clearly, these early changes occur rapidly but, as

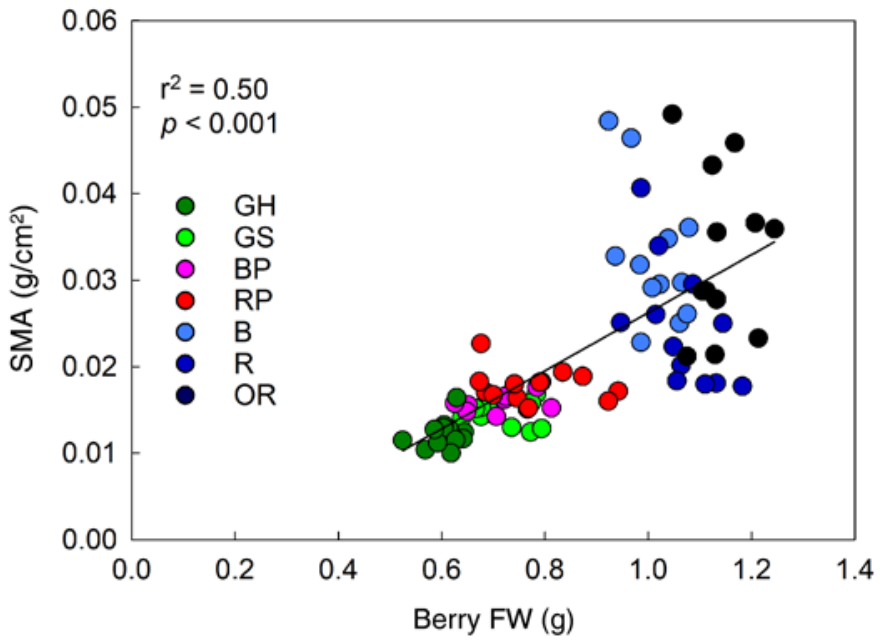

Figure 7 Relationship between fresh weight (FW) and skin mass per area ratio (SMA) across seven developmental stages $(\mathrm{GH}=$ green hard; $\mathrm{GS}=$ green soft; $\mathrm{BP}=$ blush/pink; RP = red/purple; $\mathrm{B}=$ blue; $\mathrm{R}=$ ripe; $\mathrm{OR}$ = overripe) of Merlot grape berries in southeastern Washington in 2016. Each symbol represents a sample of 12 to 15 berries.

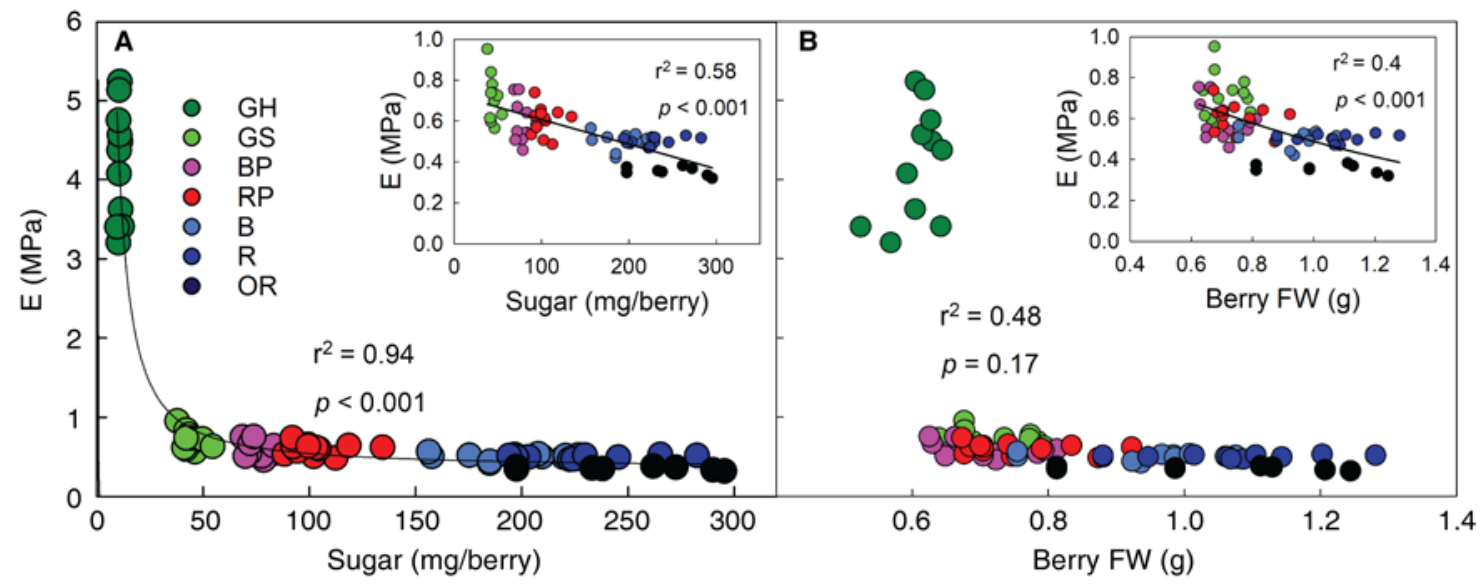

Figure 6 Relationship between elastic modulus (E) and berry sugar content $(\mathbf{A})$ and between $E$ and fresh weight (FW; B) across seven developmental stages $(\mathrm{GH}=$ green hard; GS = green soft; $\mathrm{BP}=$ blush/pink; RP = red/ purple; $\mathrm{B}=$ blue; $\mathrm{R}$ = ripe; $\mathrm{OR}$ = overripe) of Merlot grape berries in southeastern Washington in 2016. Inset shows the same relationship with $\mathrm{GH}$ berries excluded. Each symbol represents a sample of 12 to 15 berries. 
discussed below, they do not all occur simultaneously. Consequently, regardless of whether veraison is defined as, e.g., " $50 \%$ color change" or "berry softening," a random berry sample typically contains berries of at least four of the seven developmental stages defined here. Based on the present results we contend that it is not meaningful to apply the term "veraison" to individual berries; it should be reserved for populations of berries, such as all berries on a vine or in a vineyard or region.

Our results highlight the tremendous variability of physical and chemical properties across individual berries sampled at the same time point and show that major changes in these traits do not all occur at the same time or at the same rates.
The first and most drastic change we observed at the onset of grape ripening was the sudden softening that was easily determined by touch and measured as an abrupt increase in deformation upon compression and a decline in E. Similar abrupt changes in rheological properties of berries at the onset of ripening were reported by Coombe (1992) and Chang et al. (2019) for different grape genotypes and were found to be associated with a sudden drop in the resistance to splitting as the berries transitioned from GH to GS. By comparison, the resumption of berry expansion, measured as an increase in FW or diameter, was much more gradual in both the present study and previous ones (Zhang and Keller 2015, 2017, Chang et al. 2019). Moreover, berry expansion began several days

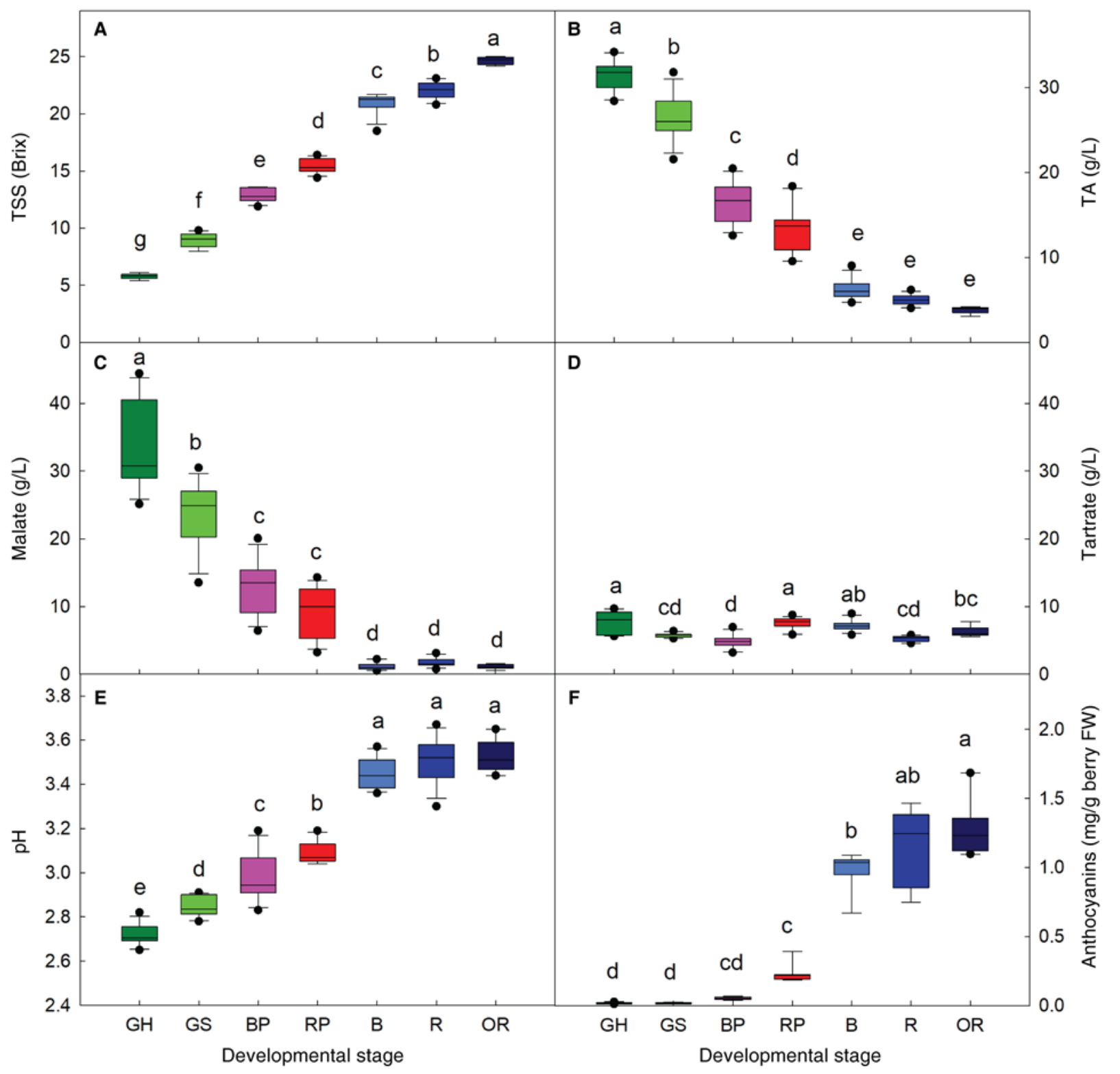

Figure 8 Changes in concentrations of total soluble solids (TSS; $\mathbf{A})$, titratable acidity (TA; $\mathbf{B})$, malate (C), tartrate (D), pH (E), and anthocyanins (F) across seven developmental stages $(\mathrm{GH}=$ green hard; $\mathrm{GS}=$ green soft; $\mathrm{BP}=$ blush/pink; RP = red/purple; $\mathrm{B}=$ blue; $\mathrm{R}=$ ripe; OR = overripe) of Merlot grape berries in southeastern Washington in 2016. The central line in each box plot indicates the median, box boundaries indicate the 25th and 75th percentiles, whiskers indicate the 10th and 90th percentiles, black circles represent outliers outside the 5th and 95th percentiles. Different letters indicate significant differences among developmental stages according to Tukey's test ( $p<0.05, n=12$ samples of 12 to 15 berries each). 
after the initial softening. Based on sequential measurements of individual berries, Coombe (1992) reported a six-day lag between softening and the resumption of berry expansion. The increase in SMA in the expanding berries observed here was similar to the correlation between berry and skin FW found previously (Keller et al. 1998) and suggests that the skin thickness and/or density increased during ripening. However, we currently have no satisfactory explanation for the large variation in SMA that appeared once the berries turned blue.

Although the decline in E associated with berry softening happened rapidly and mostly before any sugar was accumulated and before the berries resumed growth, the correlation between $\mathrm{E}$ and sugar content in soft $(\mathrm{E}<1 \mathrm{MPa})$ berries suggests that some softening continues during ripening. Using calendar-based sampling (i.e., days after anthesis), Thomas et al. (2008) and Castellarin et al. (2016) reported a decrease in E prior to and during sugar accumulation, while Coombe (1992) found the beginning of softening and sugar accumulation to coincide. Softening likely occurs because of the loosening of cell walls in the berry flesh, which is coupled to a decrease in turgor, while the subsequent cell wall loosening in the skin enables the berry to expand due to the influx of sugar and water via the phloem (Huang and Huang 2001, Thomas et al. 2008, Keller et al. 2015, Castellarin et al. 2016,
Zhang and Keller 2017). The continued but small decrease in E beyond the GS stage probably reflects the gradual flesh cell wall degradation that occurs during grape ripening (Huang et al. 2005). Moreover, there was a striking similarity in the TSS threshold (22.5 Brix) at which there was a final small drop in E in this study and at which the apoplast-symplast $\mathrm{pH}$ gradient collapsed in Merlot berries (Keller and Shrestha 2014), even though the two studies were conducted in different years and different vineyards. It is conceivable that the two events both reflect a loss in mesocarp cell membrane integrity in mature berries (Fuentes et al. 2010) and are coupled to a decline in sugar import via the phloem (Zhang and Keller 2017). This interpretation is supported by the similarity in sugar content, but not TSS concentration, between the R and OR stages in this study.

Immediately after the initial berry softening, sugar began to accumulate in the berries and malate declined, driving a decrease in TA and increase in $\mathrm{pH}$. Sugar accumulated rapidly in concert with berry growth as the berries of all cultivars tested here changed color. Evidently, individual grape berries, rather than whole clusters, temporarily become very strong sinks at the onset of ripening, confirming results obtained in studies of vascular flows in grape berries (Keller et al. 2015, Zhang and Keller 2017). At the same time, malate (but not tartrate) catabolism and anthocyanin accumulation

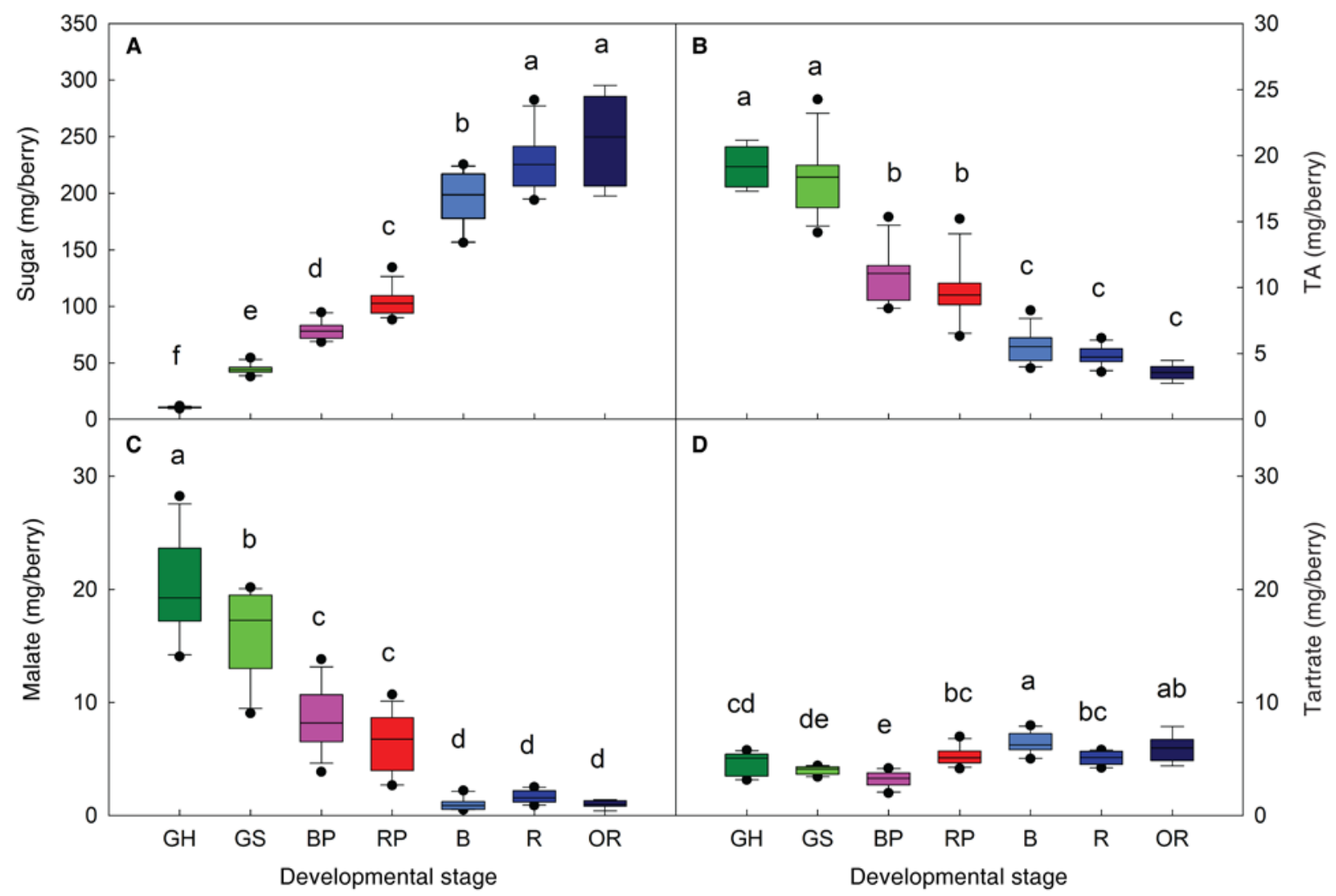

Figure 9 Changes in content per berry of sugar (A), titratable acidity (TA; B), malate (C), and tartrate (D) across seven developmental stages (GH = green hard; $\mathrm{GS}=$ green soft; $\mathrm{BP}=$ blush/pink; $\mathrm{RP}=$ red/purple; $\mathrm{B}=$ blue; $\mathrm{R}=$ ripe; $\mathrm{OR}=$ overripe) of Merlot grape berries in southeastern Washington in 2016. The central line in each box plot indicates the median, box boundaries indicate the 25th and 75th percentiles, whiskers indicate the 10th and 90th percentiles, black circles represent outliers outside the 5th and 95th percentiles. Different letters indicate significant differences among developmental stages according to Tukey's test ( $p<0.05, \mathrm{n}=12$ samples of 12 to 15 berries each). 
proceeded rapidly in the Merlot berries measured here. Because the changes in malate accounted for more than $90 \%$ of the changes in TA, measurements of TA essentially serve as a proxy for ripening-related decreases in malate. Nevertheless, the overall variation in TA predicted more of the variation in $\mathrm{pH}(95 \%)$ than did malate $(89 \%)$.

After the berries reached $\sim 17$ Brix and turned blue, the increase in sugar and anthocyanin content slowed and berry

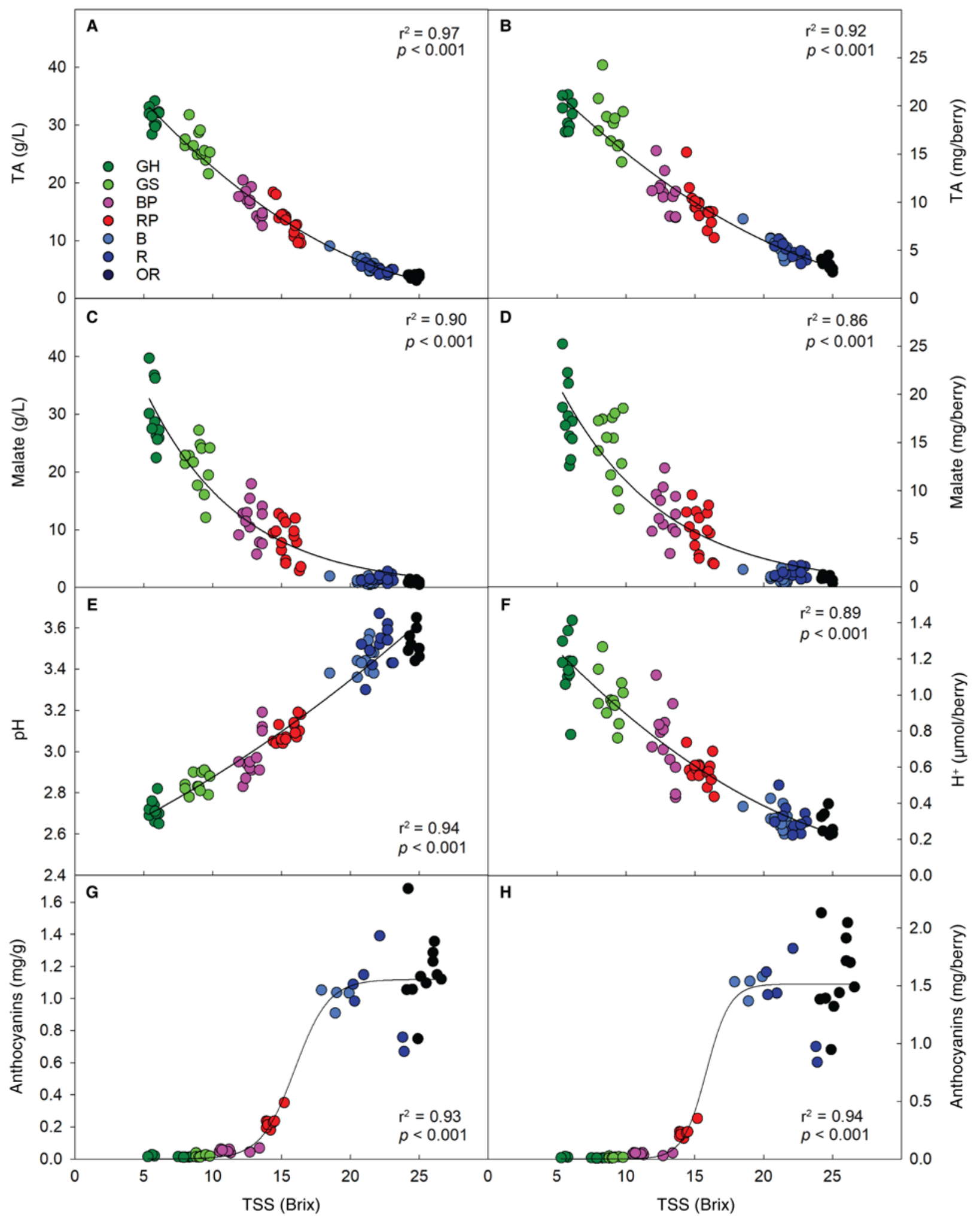

Figure 10 Relationship between total soluble solids (TSS) and titratable acidity (TA; A, B), malate (C, D), pH (E), protons ( $\left.\mathrm{H}^{+} ; \mathbf{F}\right)$, and anthocyanins $(\mathbf{G}, \mathbf{H})$ across seven developmental stages $(\mathrm{GH}=$ green hard; $\mathrm{GS}=$ green soft; $\mathrm{BP}=$ blush/pink; $\mathrm{RP}=$ red/purple; $\mathrm{B}=\mathrm{blue} ; \mathrm{R}=$ ripe; OR = overripe) of Merlot grape berries in southeastern Washington in 2016. Panels A, C, E, G show concentrations, and panels B, D, F, H show contents per berry. Each symbol represents a sample of 12 to 15 berries. 


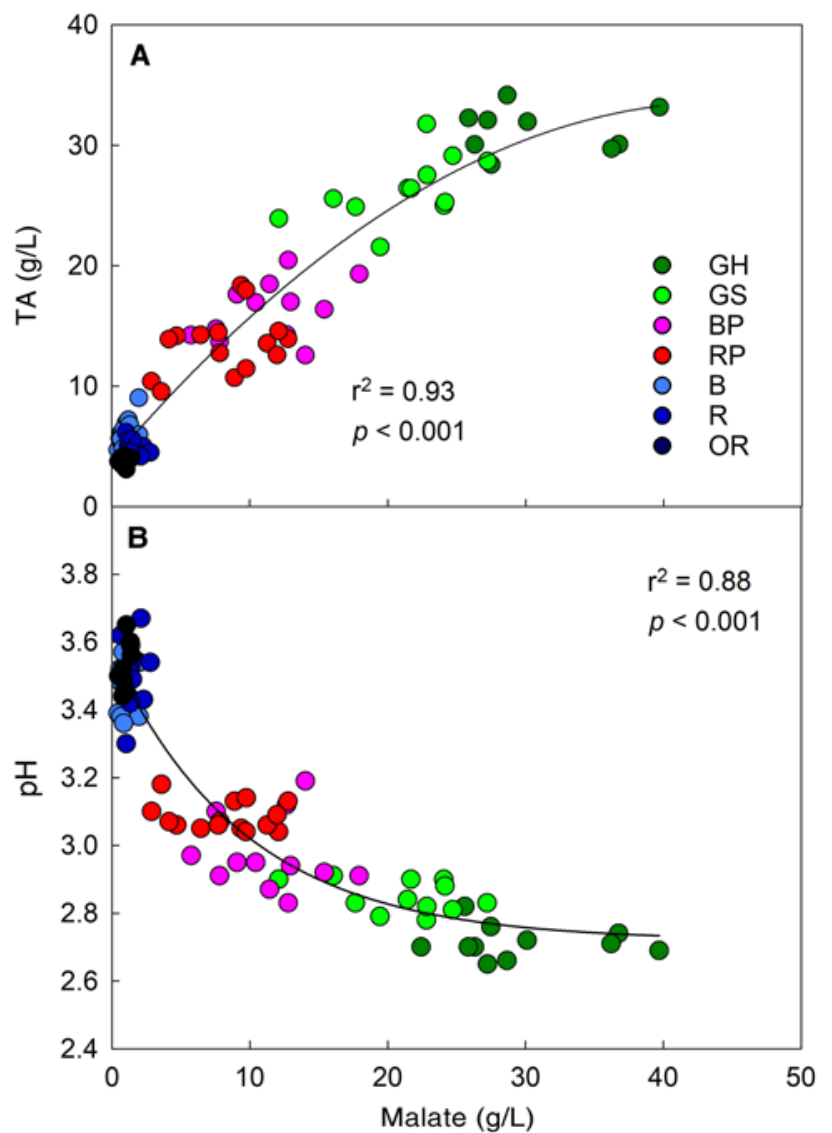

Figure 11 Relationship between malate and titratable acidity (TA; A) and $\mathrm{pH}(\mathbf{B})$ across seven developmental stages $(\mathrm{GH}=$ green hard; $\mathrm{GS}$ = green soft; $\mathrm{BP}=$ blush/pink; $\mathrm{RP}=$ red/purple; $\mathrm{B}=$ blue; $\mathrm{R}=$ ripe; $\mathrm{OR}$ = overripe) of Merlot grape berries in southeastern Washington in 2016. Each symbol represents a sample of 12 to 15 berries.

expansion and malate degradation ceased, leaving a small pool of residual malate, in agreement with earlier research (e.g., Famiani et al. 2016). Sugar accumulation and malate degradation occurred simultaneously and were closely correlated, suggesting that the two processes may be tightly linked, at least until most malate has disappeared above 17 Brix. Consistent with this view, it has been proposed that the activation of hexose import for storage in the berry vacuoles could trigger malate export from the vacuoles to compensate for the depletion in the cytosol of sugar available for glycolysis and respiration (Sarry et al. 2004, Keller and Shrestha 2014). However, from the GH to the RP stage, both the concentration and the content of malate were much more variable among samples than those of sugar and tartrate. This suggests that malate metabolism in grape berries is more responsive to environmental effects than is sugar accumulation and tartrate metabolism. Although we know little about the environmental sensitivity of tartrate metabolism, malate catabolism during grape ripening is known to be strongly driven by temperature (Kliewer 1973, Sweetman et al. 2014).

In agreement with Castellarin et al. (2016), our results showed that anthocyanins start to accumulate in grape berries only after the majority of berry softening has occurred and after the berries have begun to accumulate sugars. Thus,

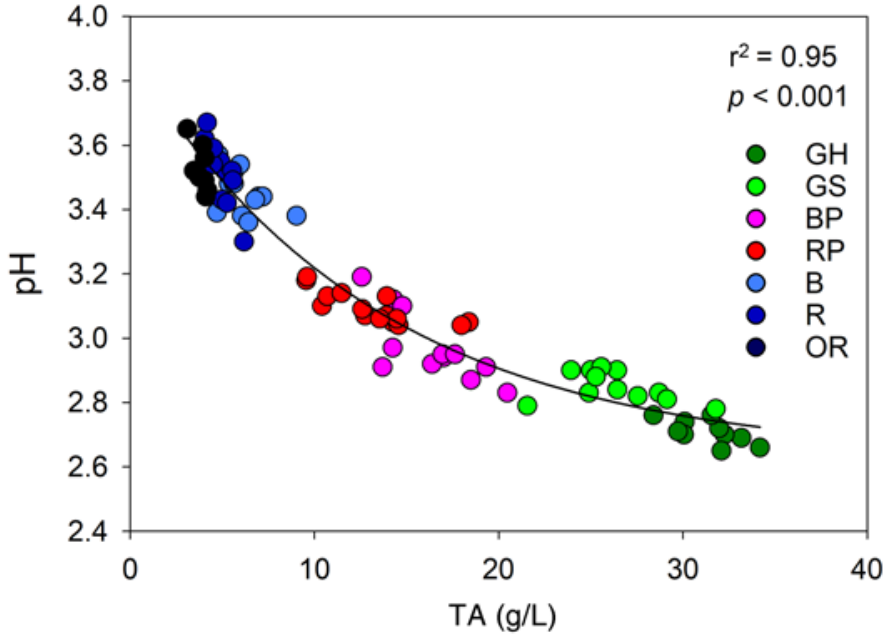

Figure 12 Relationship between titratable acidity (TA) and $\mathrm{pH}$ across seven developmental stages $(\mathrm{GH}=$ green hard; $\mathrm{GS}=$ green soft; $\mathrm{BP}=$ blush/pink; RP = red/purple; $\mathrm{B}=$ blue; $\mathrm{R}=$ ripe; $\mathrm{OR}=$ overripe) of Merlot grape berries in southeastern Washington in 2016. Each symbol represents a sample of 12 to 15 berries.

the common notion that color change marks the beginning of the ripening phase (Coombe 1992) is incorrect. Our data also highlight an error in the standard $\mathrm{BBCH}$ scale that is widely used to describe grapevine phenological stages (Lorenz et al. 1994). The scale lists stage 81 as "beginning of ripening," stage 83 as "berries brightening in color," and stage 85 as "softening of berries." Our data showed that almost all of the decrease in berry E occurred at $\sim 5$ Brix and before the sugar content began to increase, and that GH and GS berries typically could not be distinguished visually. These results were consistent across 10 cultivars of wine, table, and juice grapes and over three growing seasons. Therefore, berry softening can be regarded as the first perceptible indicator of grape ripening, and color change starts several days later. Once sugar accumulation began, we found a TSS threshold of 10 Brix for the beginning of anthocyanin accumulation in Merlot grape skins. This agrees well with the previously published threshold of 9 to 10 Brix that was found to be independent of plant water and nutrient status and light environment (Hrazdina et al. 1984, Keller and Hrazdina 1998, Castellarin et al. 2007). Indeed, sugars, in concert with abscisic acid, are thought to trigger anthocyanin biosynthesis in grape berries as well as leaves (Pirie and Mullins 1976, Castellarin et al. 2011, 2016, Halldorson and Keller 2018, Keller 2020).

\section{Conclusions}

The results of this study demonstrated that stratified sampling during and after veraison can be applied in both darkand light-skinned, seeded wine- and juice grape cultivars and seedless table grape cultivars. This sampling approach is robust with respect to operators and is reproducible across diverse cultivars and growing seasons. It permits assigning grape berries from clusters undergoing veraison to multiple ripening groups, which are usually lumped together with calendar- or phenology-based sampling. The data also showed the massive and rapid changes that occur in grape berries at 
the beginning of ripening, the sequence and variability of the measured physical and chemical properties, and key relationships between them. Among the properties measured here, sudden berry softening marks the onset of grape ripening and is quickly followed by the beginning of sugar accumulation, berry expansion, malate catabolism, and finally, anthocyanin accumulation in dark-skinned cultivars. Consequently, to understand veraison, each of the developmental stages that comprise this phenological phase should be considered separately. We conclude that the term "veraison" applies to grape berry populations at various levels (e.g., cluster, vine, vineyard, or region) and cannot be meaningfully applied to individual berries.

\section{Literature Cited}

Bigard A, Romieu C, Sire Y, Veyret M, Ojéda H and Torregrosa L. 2019. The kinetics of grape ripening revisited through berry density sorting. OENO One 53:709-724.

Castellarin SD, Pfeiffer A, Sivilotti P, Degan M, Peterlunger E and Di Gaspero G. 2007. Transcriptional regulation of anthocyanin biosynthesis in ripening fruits of grapevine under seasonal water deficit. Plant Cell Environ 30:1381-1399.

Castellarin SD, Gambetta GA, Wada H, Shackel KA and Matthews MA. 2011. Fruit ripening in Vitis vinifera: Spatiotemporal relationships among turgor, sugar accumulation, and anthocyanin biosynthesis. J Exp Bot 62:4345-4354.

Castellarin SD, Gambetta GA, Wada H, Krasnow MN, Cramer GR, Peterlunger E, Shackel KA and Matthews MA. 2016. Characterization of major ripening events during softening in grape: Turgor, sugar accumulation, abscisic acid metabolism, colour development, and their relationship with growth. J Exp Bot 67:709-722.

Chang BM, Zhang Y and Keller M. 2019. Softening at the onset of grape ripening alters rheological properties and decreases splitting resistance. Planta 250:1293-1305.

Coombe BG. 1992. Research on development and ripening of the grape berry. Am J Enol Vitic 43:101-110.

Famiani F, Farinelli D, Frioni T, Palliotti A, Battistelli A, Moscatello S and Walker RP. 2016. Malate as substrate for catabolism and gluconeogenesis during ripening in the pericarp of different grape cultivars. Biol Plant 60:155-162.

Famiani F, Paoletti A, Proietti P, Battistelli A, Moscatello S, CruzCastillo JG and Walker RP. 2018. The occurrence of phosphoenolpyruvate carboxykinase (PEPCK) in the pericarp of different grapevine genotypes and in grape leaves and developing seeds. J Hortic Sci Biotech 93:456-465.

Fasoli M, Richter CL, Zenoni S, Bertini E, Vitulo N, Dal Santo S, Dokoozlian N, Pezzotti M and Tornielli GB. 2018. Timing and order of the molecular events marking the onset of berry ripening in grapevine. Plant Physiol 178:1187-1206.

Fuentes S, Sullivan W, Tilbrook J and Tyerman S. 2010. A novel analysis of grapevine berry tissue demonstrates a variety-dependent correlation between tissue vitality and berry shrivel. Aust J Grape Wine Res 16:327-326.

Gillaspy G, Ben-David H and Gruissem W. 1993. Fruits: A developmental perspective. Plant Cell 5:1439-1451.

Gouthu S and Deluc LG. 2015. Timing of ripening initiation in grape berries and its relationship to seed content and pericarp auxin levels. BMC Plant Biol 15:46.

Gouthu S, O'Neill ST, Di Y, Ansarolia M, Megraw M and Deluc LG. 2014. A comparative study of ripening among berries of the grape cluster reveals an altered transcriptional programme and enhanced ripening rate in delayed berries. J Exp Bot 65:5889-5902.

Halldorson MM and Keller M. 2018. Grapevine leafroll disease alters leaf physiology but has little effect on plant cold hardiness. Planta 248:1201-1211.

Hrazdina G, Parsons GF and Mattick LR. 1984. Physiological and biochemical events during development and maturation of grape berries. Am J Enol Vitic 35:220-227.

Huang XM and Huang HB. 2001. Early post-veraison growth in grapes: Evidence for a two-step mode of berry enlargement. Aust J Grape Wine Res 7:132-136.

Huang XM, Huang HB and Wang HC. 2005. Cell walls of loosening skin in post-veraison grape berries lose structural polysaccharides and calcium while accumulate structural proteins. Sci Hortic 104:249-263.

Iland PG, Cynkar WC, Francis IL, Williams PJ and Coobe BG. 1996. Optimisation of methods for the determination of total and red-free glycosyl glucose in black grape berries of Vitis vinifera. Aust J Grape Wine Res 2:171-178.

Keller M. 2020. The Science of Grapevines. 3rd ed. Elsevier Academic Press, London, UK.

Keller M and Hrazdina G. 1998. Interaction of nitrogen availability during bloom and light intensity during veraison: II. Effects on anthocyanin and phenolic development during grape ripening. Am J Enol Vitic 49:341-349.

Keller M and Shrestha PM. 2014. Solute accumulation differs in the vacuoles and apoplast of ripening grape berries. Planta 239:633-642.

Keller M, Arnink KJ and Hrazdina G. 1998. Interaction of nitrogen availability during bloom and light intensity during veraison I. Effects on grapevine growth, fruit development, and ripening. Am J Enol Vitic 49:333-340.

Keller M, Smith JP and Bondada BR. 2006. Ripening grape berries remain hydraulically connected to the shoot. J Exp Bot 57:2577-2587.

Keller M, Zhang Y, Shrestha PM, Biondi M and Bondada BR. 2015. Sugar demand of ripening grape berries leads to recycling of surplus phloem water via the xylem. Plant Cell Environ 38:1048-1059.

Keller M, Shrestha PM, Hall GE, Bondada BR and Davenport JR. 2016. Arrested sugar accumulation and altered organic acid metabolism in grape berries affected by berry shrivel syndrome. Am J Enol Vitic 67:398-406.

Kliewer WM. 1973. Berry composition of Vitis vinifera cultivars as influenced by photo- and nycto-temperatures during maturation. J Am Soc Hort Sci 98:153-159.

Kuhn N et al. 2014. Berry ripening: Recently heard through the grapevine. J Exp Bot 65:4543-4559.

Lorenz DH, Eichhorn KW, Bleiholder H, Klose R, Meier U and Weber E. 1994. Phänologische entwicklungsstadien der weinrebe (Vitis vinifera L. ssp. vinifera) — codierung und beschreibung nach der erweiterten BBCH-Skala. Wein-Wiss 49:66-70.

Lund ST, Peng FY, Nayar T, Reid KE and Schlosser J. 2008. Gene expression analyses in individual grape (Vitis vinifera L.) berries during ripening initiation reveal that pigmentation intensity is a valid indicator of developmental staging within the cluster. Plant Mol Biol 68:301-315.

Pirie A and Mullins MG. 1976. Changes in anthocyanin and phenolics content of grapevine leaf and fruit tissues treated with sucrose, nitrate, and abscisic acid. Plant Physiol 58:468-72.

Saladié $M$ et al. 2007. A reevaluation of the key factors that influence tomato fruit softening and integrity. Plant Physiol 144:1012-1028.

Sarry JE, Sommerer N, Sauvage FX, Bergoin A, Rossignol M, Albagnac $\mathrm{G}$ and Romieu C. 2004. Grape berry biochemistry revisited upon proteomic analysis of the mesocarp. Proteomics 4:201-215. 
Savoi S, Herrera JC, Forneck A and Griesser M. 2019. Transcriptomics of the grape berry shrivel ripening disorder. Plant Mol Biol 100:285-301.

Schneider CA, Rasband WS and Eliceiri KW. 2012. NIH Image to ImageJ: 25 years of image analysis. Nat Methods 9:671-675.

Sweetman C, Sadras VO, Hancock RD, Soole KL and Ford CM. 2014. Metabolic effects of elevated temperature on organic acid degradation in ripening Vitis vinifera fruit. J Exp Bot 65:5975-5988.

Thomas TR, Shackel KA and Matthews MA. 2008. Mesocarp cell turgor in Vitis vinifera L. berries throughout development and its relation to firmness, growth, and the onset of ripening. Planta 228:1067-1076.

Vondras AM, Gouthu S, Schmidt JA, Petersen AR and Deluc LG. 2016. The contribution of flowering time and seed content to uneven ripening initiation among fruits within Vitis vinifera L. cv. Pinot noir clusters. Planta 243:1191-1202.

Zhang Y and Keller M. 2015. Grape berry transpiration is determined by vapor pressure deficit, cuticular conductance, and berry size. Am J Enol Vitic 66:454-462.

Zhang Y and Keller M. 2017. Discharge of surplus phloem water may be required for normal grape ripening. J Exp Bot 68:585-595.

Zhu M, Yu J, Zhao M, Wang M and Yang G. 2020. Transcriptome analysis of metabolisms related to fruit cracking during ripening of a cracking-susceptible grape berry cv. Xiangfei (Vitis vinifera L.). Genes Genom 42:639-650. 